FOREWORD $\ldots \ldots \ldots \ldots \ldots \ldots \ldots \ldots \ldots \ldots \ldots \ldots \ldots$ vii

DISCLAIMER $\ldots \ldots \ldots \ldots \ldots \ldots \ldots \ldots \ldots \ldots \ldots \ldots \ldots \ldots \ldots$ viii

ACKNOWLEDGMENTS $\ldots \ldots \ldots \ldots \ldots \ldots \ldots \ldots \ldots$ ix

ABSTRACT $\ldots \ldots \ldots \ldots \ldots \ldots \ldots \ldots \ldots \ldots \ldots \ldots \ldots \ldots \ldots \ldots$

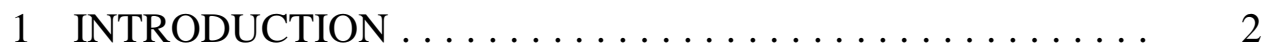

2 INSTALLING THE ORAMUS SYSTEM . . . . . . . . . . 8

Windows 3.1 and Windows 95 Installation . . . . . . . . . 8

DOS Installation $\ldots \ldots \ldots \ldots \ldots \ldots \ldots \ldots$

3 GETTING TO KNOW THE ORAMUS SYSTEM $\ldots . . \ldots \ldots .11$

4 HEADCOUNT RISKS FOR ACUTE ENDPOINTS . . . . . . . 17

Choosing between Acute and Chronic Health Endpoints . . . . 17

Computing Selected Risk Results for Acute

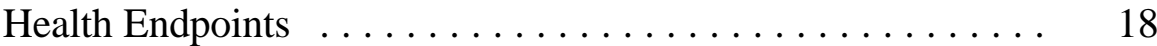

Directory Structure and File Naming Conventions . . . . . . . . 21

Specifying Active Air Quality Scenarios . . . . . . . . . . . . 22

Viewing Risk Results as Probability Distributions . . . . . . . . 23

Representative Distributions and Vector

Graphics Images . . . . . . . . . . . . . . . 26

Differences between the Reference Scenario

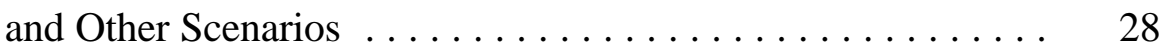

Viewing Risk Results in Box Plot Format . . . . . . . . . . . . 29

Creating a Vector Graphics Image File . . . . . . . . . . . . 32

5 HOSPITAL ADMISSIONS MODEL $\ldots \ldots \ldots \ldots \ldots \ldots \ldots$

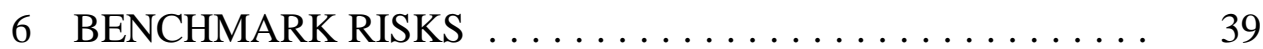




\section{CONTENTS (Cont.)}

7 FINAL NOTES $\ldots \ldots \ldots \ldots \ldots \ldots \ldots \ldots \ldots \ldots \ldots \ldots \ldots$

An Extra Utility — LOOKERF.EXE . . . . . . . . . . . . 43

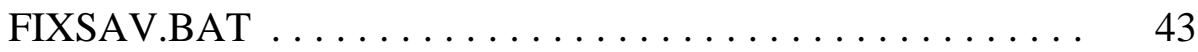

GEN.EXE — A Vector Graphics Generator . . . . . . . . . . 44

Installation and Use of the ORAMUS Source Code . . . . . . . 45

Sample Output Files . . . . . . . . . . . . . . . . . 46

Running ORAMUS Executables Directly in DOS ......... 46

8 REFERENCES $\ldots \ldots \ldots \ldots \ldots \ldots \ldots \ldots \ldots \ldots \ldots \ldots \ldots \ldots$

APPENDIX A: Formats of Principal Input and Output Files . . . . 50

APPENDIX B: Information about Health Endpoints and Air Quality Scenarios Used in ORAMUS . . . . . . . . . . 62

\section{FORMS AND EXAMPLES}

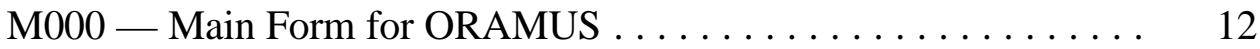

Keystrokes for Moving around in Forms $\ldots \ldots \ldots \ldots \ldots \ldots$

Screen Colors for Forms $\ldots \ldots \ldots \ldots \ldots \ldots \ldots \ldots$

Example of Help Documentation for ORAMUS Forms . . . . . . . . 14

H000 — Main Form for Headcount Risk Models . . . . . . . . . . . 16

A000 - Setup Form for Computing or Viewing

Risk Results for Acute Health Endpoints . . . . . . . . . . . 19

A000 - Setup Form for Computing Selected Risk Results

for Acute Health Endpoints $\ldots \ldots \ldots \ldots \ldots \ldots$

PickAQS — Form for Selecting Active Air Quality Scenarios . . . . 22

A Set of 10 Risk Distributions for Each of 2 Air

Quality Scenarios ....................... 24 
FORMS AND EXAMPLES (Cont.)

P502 — Form for Controlling Graph Properties . .......... 25

P502A — Form for Controlling Properties of a WordPerfect

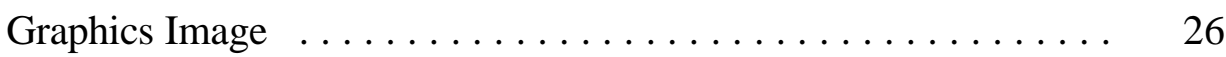

Example of a WordPerfect Graphics Image $\ldots \ldots \ldots \ldots \ldots \ldots \quad 27$

Differences between the Reference Representative

Distribution and Other Distributions $\ldots \ldots \ldots \ldots \ldots \ldots \ldots .28$

GENBOX1 - Form for Specifying the Contents

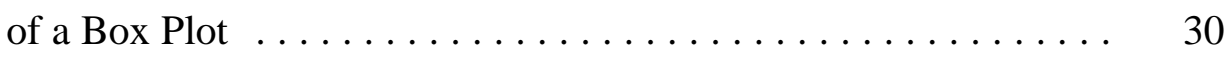

GENBOX2 - Form for Specifying the Appearance

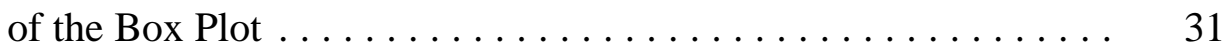

Vector Graphics Image of the Box Plot Format

for Acute Risk Results $\ldots \ldots \ldots \ldots \ldots \ldots \ldots \ldots \ldots, \quad 32$

HOSP - Setup Form for Hospital Admissions

Model Calculations ........................ 34

Excess Annual Admissions of Asthmatics in New York City ..... 36

BMBOX2 - Form for Selecting Benchmark Risk

Results for Graphing $\ldots \ldots \ldots \ldots \ldots \ldots \ldots \ldots \ldots \ldots \ldots \ldots \ldots \ldots \ldots$

Sample Benchmark Risk Graph $\ldots \ldots \ldots \ldots \ldots \ldots \ldots \ldots . \quad 42$

\section{TABLES}

1 Approximate Disk Space Required for Installing ORAMUS Compared with Cluster Size $\ldots \ldots \ldots \ldots \ldots . \quad 8$

2 Schematic for ORAMUS $\ldots \ldots \ldots \ldots \ldots \ldots \ldots \ldots \ldots$

3 File Naming Conventions for Acute Health Endpoints ...... 21 


\section{TABLES (Cont.)}

4 Data for Risk Distributions and Statistics Concerning the Results for the Hospital Admissions Model . . . . . . . . 38

A.1 Exposure Probability File for Headcount Risk

Endpoints: Philadelphia, Children, 8-hour

Exposures, Scenario $1112 \ldots \ldots \ldots \ldots$

A.2 Portion of an Exposure-Response Relationship File for Headcount Risks: $\mathrm{FEV}_{1} \geq 20 \%, 8$-hour Exposures at Moderate Exertion ................. 53

A.3 Risk Results File for Headcount Risks: $\mathrm{FEV}_{1} \geq 20 \%$, Philadelphia, Outdoor Children, Scenario $1112 \ldots \ldots \ldots 54$

A.4 Air Quality Data File for the Hospital Admissions Model . . . 57

A.5 Benchmark Risk Results File . . . . . . . . . . . . . 59

B.1 Human Exposure Studies that Support Acute Health Endpoints ................. 63

B.2 Air Quality Scenarios Available for Acute Risk Assessments . . . . . . . . . . . . . . . . . . . 64 
The ORAMUS (Ozone Risk AssessMent UtilitieS) code and this documentation were prepared for the U.S. Environmental Protection Agency (EPA) under a contract with the U.S. Department of Energy (DOE). Any distribution of the software package, or other data therein, outside of EPA or DOE offices or contractors, unless otherwise specifically provided for, is prohibited without the approval of the Energy Science and Technology Software Center. Requests from outside DOE for DOEdeveloped computer software should be directed to the Energy Science and Technology Software Center, P.O. Box 1020, Oak Ridge, TN 37831-1020; phone 423-576-2606. 
This work was funded through Interagency Agreement DW89935085-01-3 between the U.S. Environmental Protection Agency (EPA) and the U.S. Department of Energy (DOE). Any opinions, findings, conclusions, or recommendations are those of the authors and do not necessarily reflect the views of reviewers, people named in the acknowledgments, the EPA, the DOE, or Argonne National Laboratory. Comments concerning the report should be addressed to Harvey Richmond, U.S. Environmental Protection Agency, Office of Air Quality Planning and Standards, MD-15, Research Triangle Park, NC 27711. 


\section{ACKNOWLEDGMENTS}

The ORAMUS (Ozone Risk AssessMent UtilitieS) software package is a result of the support and encouragement of Harvey M. Richmond and Karen Martin from the U.S. Environmental Protection Agency, Office of Air Quality Planning and Standards. Additional software tools (which are not a part of ORAMUS) for calculating benchmark risk results were developed by Dr. William F. Biller under U.S. Environmental Protection Agency contract number 68D30092.

The authors also extend their appreciation to the Information and Publishing Division (IPD) at Argonne National Laboratory.

Don Timmerman (Technical Communication Services) assisted in validating ORAMUS. IPD's Document Processing and Control Center prepared the final manuscript. 


\title{
OZONE RISK ASSESSMENT UTILITIES (ORAMUS) USER'S MANUAL AND TUTORIAL: VOLUME 1, ACUTE HEALTH ENDPOINTS
}

\author{
R.G. Whitfield, M.J. Jusko, and M.A. Clemmons
}

\section{ABSTRACT}

The primary purpose of this manual is to provide instructions on how to install and use the ORAMUS (Ozone Risk AssessMent UtilitieS) software. ORAMUS is a DOS-based software system that allows you to calculate and view risk estimates for health effects attributable to short- and longterm exposure to tropospheric ozone. The system combines exposure estimates with exposure-response relationships and then calculates and displays estimates of the overall risk in the form of probability distributions. ORAMUS allows you to select from three basic models: headcount risk, benchmark risk, and hospital admissions. It calculates a wide range of risk results for 27 air quality scenarios, 9 urban areas, 33 acute health endpoints, 4 chronic health endpoints, and 3 populations of interest. This manual is a tutorial designed to guide you through a series of steps that will familiarize you with the features of the system. The manual consists of two volumes. Volume 1 addresses acute health endpoints, and Volume 2 covers chronic health endpoints. Acute results were used during the National Ambient Air Quality Standards review process for ozone. Chronic results were not used. 


\section{INTRODUCTION}

The primary purpose of this manual is to provide instructions on the installation and use of the ORAMUS (Ozone Risk AssessMent UtilitieS) software. The manual is a tutorial; that is, you will be instructed to perform steps designed to help you become familiar with the program's functions. You can obtain more details about the format, interpretation of the results, and types of figures that can be created in ORAMUS by examining detailed reports by Whitfield (1997a,b) and Whitfield et al. (1996). Some of the basic capabilities of ORAMUS are described in this section. If you are already familiar with these capabilities, you can proceed directly to Section 2, which contains the instructions for installing ORAMUS on your IBMcompatible personal computer (PC).

ORAMUS produces risk results by combining exposure-response relationships with air quality and exposure estimates for alternative National Ambient Air Quality Standards (NAAQS) for ozone. The risks are described in terms of three basic types of health endpoints:

$<$ Hospital admissions of asthmatics or patients with various respiratory problems;

$<$ Acute health effects, such as coughing, chest pain when taking a deep breath, and decreased forced expiratory volume; and

$<$ Chronic health effects, such as the formation of lesions in the centriacinar region of the human lung.

Refer to Volume 2 for instructions on using the chronic risk assessment capabilities of ORAMUS.

Two fundamental types of risk measures are used:

$<$ Headcount risk: Headcount risk refers to the number of persons or the number of times individuals from a specific population experience a particular "event," that is, a hospital admission, cough, chest pain, or decreased lung function. Included in the headcount risk measure is the percentage of possible events estimated to occur. This measure of risk combines exposure-response relationships with exposure 
estimates about various populations as they go about their daily activities. The hospital admissions measure is a type of headcount risk.

To obtain headcount risk distributions, ORAMUS combines probabilistic exposure-response relationships with exposure estimates. Acute relationships are derived from various sources, primarily experimental and observational data for acute effects in humans. Chronic relationships are the result of expert judgment. Exposure estimates, which are also probabilistic, were obtained from the recently developed probabilistic version of the NAAQS exposure model for ozone $\left(\mathrm{pNEM}^{\mathrm{N}} \mathrm{O}_{3}\right)$. The output from $\mathrm{pNEM} / \mathrm{O}_{3}$ includes results for 10 separate runs of the model, which allow you to gain insights about the effects of run-to-run variations on risk output. Precursors to $\mathrm{pNEM} / \mathrm{O}_{3}$ have been described by Paul et al. (1986), Johnson et al. (1990), McCurdy et al. (1991), and McCurdy (1994). Exposure estimates used in ORAMUS have been developed and are described by Johnson (1997) and Johnson et al. (1996a-c, 1997).

< Benchmark risk: Benchmark risk is a measure of the hazard posed by elevated ambient ozone levels. It is calculated by assuming that all members of the at-risk population are exposed outdoors under identical exposure conditions. In contrast to the headcount risk, benchmark risk focuses on the probability, or risk, of unhealthful air.

Benchmark response $r$ is the fraction of the population that may experience a specific health effect when exposed to ozone. Benchmark risk is the probability that the benchmark response is $\$ r, n$ or more times in a specified period (one ozone season) at some location within a geographic region, given a particular air quality condition (e.g., that Scenario 1112 [see description on page 5] is just attained). The software accommodates $r$ values of $0.01,0.05$, and 0.1 (sometimes referred to as 0.01 , 0.05 , and 0.1 benchmarks or $1 \%, 5 \%$, and $10 \%$ benchmarks, respectively).

Headcount risks are represented by probability distributions (also called risk distributions) over a variety of risk measures. An example of a risk 
measure is the number of children who spend considerable time outdoors (outdoor children) and may experience pain on deep inspiration that can be attributed to exposure to tropospheric ozone during one ozone season in Los Angeles. Probability distributions generally are needed to represent the risks fairly because of the considerable uncertainty regarding the amount of exposure that individuals and populations receive and the degree to which they experience various health endpoints at specific exposure levels.

The hospital admissions model has elements of both the benchmark and the headcount risk models. It uses air quality data, as does the benchmark risk model, and a concentration-response relationship that resembles the exposure-response relationships used in the headcount risk model. The hospital admissions model assumes a linear relationship between hospital admissions (the response) and the previous day's highest hourly average ozone concentration as measured at a fixed-site monitor.

Risk measures are composed of several factors:

$<$ Population of interest, such as outdoor children, outdoor workers, asthmatics, and the general population;

$<$ Type of effect, such as hospital admission, coughing, chest pain, decreased lung function, and formation of lesions in the human lung;

$<$ Area of residence, for example, any of nine urban areas;

$<$ Length of exposure (1 or 8 hours for acute endpoints; 1 or 10 ozone seasons for chronic endpoints);

$<$ Numbers or percentages of children or workers; and

$<$ Method of counting multiple exposures or occurrences of an effect experienced by an individual.

Risk results also depend on alternative NAAQS, which have several components:

$<$ Averaging time (1- or 8-hour daily maximum average); 
$<$ Form of the standard (i.e., the expected exceedances in one year or $n$ 'th highest average daily maximum); and

$<$ Allowed concentration $(0.07,0.08,0.09,0.10$, or 0.12 part per million [ppm] of ozone).

Of the many possible combinations of these components, ORAMUS can analyze the following 26 NAAQS, each referenced by a scenario number based on components of that specific scenario (the derivation of the number is indicated in bold for the first scenario only; the scenario reference in parentheses gives the standard EPA designation):

< Scenario 1112 (1H1EX-0.12): 1-hour daily maximum average, 1 expected exceedance, $0.12 \mathrm{ppm}$ of ozone, which was the previous ozone 1-hour standard;

< Scenario 1110 (1H1EX-0.10): 1-hour daily maximum average, 1 expected exceedance, $0.10 \mathrm{ppm}$ of ozone;

< Scenario 8110 (8H1EX-0.10): 8-hour daily maximum average, 1 expected exceedance, $0.10 \mathrm{ppm}$ of ozone;

$<$ Scenario 8109 (8H1EX-0.09): 8-hour daily maximum average, 1 expected exceedance, $0.09 \mathrm{ppm}$ of ozone;

< Scenario 8108 (8H1EX-0.08): 8-hour daily maximum average, 1 expected exceedance, 0.08 ppm of ozone;

< Scenario 8107 (8H1EX-0.07): 8-hour daily maximum average, 1 expected exceedance, $0.07 \mathrm{ppm}$ of ozone;

< Scenario 8509 (8H5EX-0.09): 8-hour daily maximum average, 5 expected exceedances, $0.09 \mathrm{ppm}$ of ozone;

< Scenario 8508 (8H5EX-0.08): 8-hour daily maximum average, 5 expected exceedances, $0.08 \mathrm{ppm}$ of ozone;

< Scenario 1124* (1H1EX-0.124): 1-hour averaging time, 1 expected exceedance, $0.124 \mathrm{ppm}$ of ozone, which portrays the previous 1-hour ozone standard and reflects the rounding convention used to judge attainment of the standard. 
< Scenario 8394* (8HA3H-0.094): 8-hour averaging time, third highest daily maximum, 0.094 ppm of ozone;

< Scenario 8784* (8HA7H-0.084): 8-hour averaging time, seventh highest average daily maximum of $0.084 \mathrm{ppm}$ of ozone;

< Scenario 8584* (8HA5H-0.084): 8-hour averaging time, fifth highest average daily maximum of 0.084 ppm of ozone;

< Scenario 8384* (8HA3H-0.084): 8-hour averaging time, third highest average daily maximum of 0.084 ppm of ozone;

< Scenario 8294 (8HA2H-0.094): 8-hour averaging time, second highest average daily maximum of $0.094 \mathrm{ppm}$ of ozone;

< Scenario 8284 (8HA2H-0.084): 8-hour averaging time, second highest average daily maximum of $0.084 \mathrm{ppm}$ of ozone; and

< Scenario 8380 (8HA3H-0.080): 8-hour averaging time, third highest average daily maximum of $0.080 \mathrm{ppm}$ of ozone.

Note: An asterisk indicates a scenario that has three sets of air quality estimates. These sets include estimates for each of three air quality adjustment procedures: proportional (used for the first eight scenarios), Weibull, and quadratic. Johnson et al. (1997) provides additional information on these adjustment procedures.

A twenty-seventh scenario, which represents existing air quality, is referred to as the "As-Is" scenario. Data for the As-Is scenario are from either 1990 or 1991 for each urban area.

In all cases, the average level is a "daily maximum" value, that is, the highest daily 1- or 8-hour average for each day of the ozone season. Although the 1- or 8-hour average ozone concentration can exceed a specific ozone level two or more times in a given day, only one exceedance will "count" for a specific day and year.

While the previous 1-hour standard (or any new standard) actually addresses a three-year period for determining compliance, acute results are based on only one ozone season. Since air quality data were adjusted to 
simulate "just attaining" a given standard and a single ozone season, actual exposures and risks can be either lower or higher in different years during the period used to judge compliance with a standard. 
The ORAMUS system can be installed through either Windows 3.1, Windows 95, or DOS on a 486 or higher PC. Table 1 summarizes the disk requirements for the system, source code, sample output, and documentation files. On a disk with a cluster size of 32,768 Mbytes, ORAMUS requires approximately 100 Mbytes of space for installing the system, 730 Mbytes for obtaining risk results for all acute health endpoints (90 Mbytes of which are for risk results for the four acute endpoints used in EPA's review of the ozone NAAQS), and 90 Mbytes for obtaining risk results for all chronic endpoints. For a cluster size twice as large, double the requirements; for a sector size half as large, reduce the requirements by $50 \%$.

TABLE 1 Approximate Disk Space Required for Installing ORAMUS (in Megabytes) Compared with Cluster Size

\begin{tabular}{ccccc}
\hline $\begin{array}{c}\text { Cluster } \\
\text { Size }\end{array}$ & System & $\begin{array}{c}\text { Source } \\
\text { Code }\end{array}$ & $\begin{array}{c}\text { Sample } \\
\text { Output }\end{array}$ & $\begin{array}{c}\text { GEN.EXE } \\
\text { Documentation }\end{array}$ \\
\hline 8,192 & 26 & 1.1 & 1.7 & 0.4 \\
16,384 & 52 & 1.3 & 3.4 & 0.4 \\
32,768 & 103 & 1.7 & 6.8 & 0.5 \\
65,536 & 203 & 2.4 & 13.5 & 0.6 \\
131,072 & 406 & 4.5 & 27.0 & 1.0 \\
\hline
\end{tabular}

\section{Windows 3.1 and Windows 95 Installation}

Three installation disks (ORAWIN1-3) contain the Windows 3.1 and Windows 95 installation files required for the ORAMUS system. Follow the procedure below to install ORAMUS on your computer:

1. Place disk ORAWIN1 in drive a: (if your floppy disk drive is a drive other than a:, substitute the appropriate drive name for a: in the following instructions).

2. In Windows 3.1, click the Program Manager File Run command. In Windows 95, click Start, and then click Run. 
3. Type a:oramus95 and click OK.

4. Follow the prompts on the screen for installing ORAMUS. Options for installing the system, the source code, information about GEN.EXE, and sample output files are given. You also can specify that the system be installed in a new or existing directory.

During installation, a program group is created that contains ORAMUS icons. Although ORAMUS is a DOS application, installing it in Windows makes it readily available for Windows users.

\section{DOS Installation}

Three installation disks (ORADOS1-3) contain the DOS installation files for the ORAMUS system. Follow the procedure below to install ORAMUS on your computer:

1. Create an ORAMUS directory at any level on any drive and go to that directory. For example, if you want to put ORAMUS on network drive $\mathrm{y}$ : in a public directory that does not exist, enter the following commands:

$$
\begin{aligned}
& \text { y: } \\
& \text { md \public } \\
& \text { md Ipublicloramus } \\
& \text { cd \publicloramus }
\end{aligned}
$$

2. Place disk ORADOS1 in drive a: (if your floppy disk drive is a drive other than a:, substitute the appropriate drive name for a: in the following commands).

3. Enter a:orazip1 $-d *$ **.

4. Place disk ORADOS2 in drive a:.

5. Enter a:orazip2 $-\mathbf{d}$ ***. 
Output Files. For headcount risk models, the installation disks contain only the input files needed to create the output files. First, create the output files. It is recommended that you create them in large groups. While it takes only a few seconds to generate one output file, many thousands comprise the full results. Thus, it can take several hours to generate each group of output files. Once the output files have been created, you can quickly view selected results. Section 4 provides instructions on how to create and then view the results of headcount risk.

Because the output files for the benchmark risk model require nearly as much space as the input files, the installation disks include only the output files.

The results for the hospital admissions model are not very extensive because the model involves only the New York City urban area. Results of primary interest (for a specific New York City monitor) are included with the installation disks. Results for other New York City monitors can easily be generated. 


\section{GETTING TO KNOW THE ORAMUS SYSTEM}

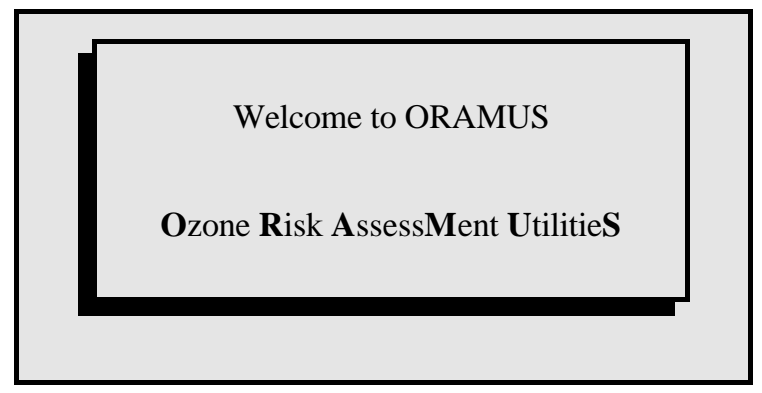

Welcome Screen for ORAMUS

Now that you have installed the ORAMUS software, you are ready to use the system. If you installed ORAMUS under Windows 3.1 or Windows 95, open the ORAMUS folder and double click on the ORAMUS icon. If you want (or need) to run under DOS, follow these steps:

1. At the DOS prompt, change to the ORAMUS directory (e.g., cd |publicloramus).

\section{Type oramus.}

\section{Press Enter.}

If the system has been installed properly, you can proceed as follows. At the Welcome screen, press any key to display the first screen, M000 (the Main Form shown on page 12).

If the system is not installed properly, Form M000 is not displayed. If you cannot reach this form, run the system a second time. After the Welcome screen, Form S000 is displayed, which is a setup form with one field in which you must enter the path to the ..IORAMUS directory. Follow the instructions given in Form S000 and press F10 to proceed. 


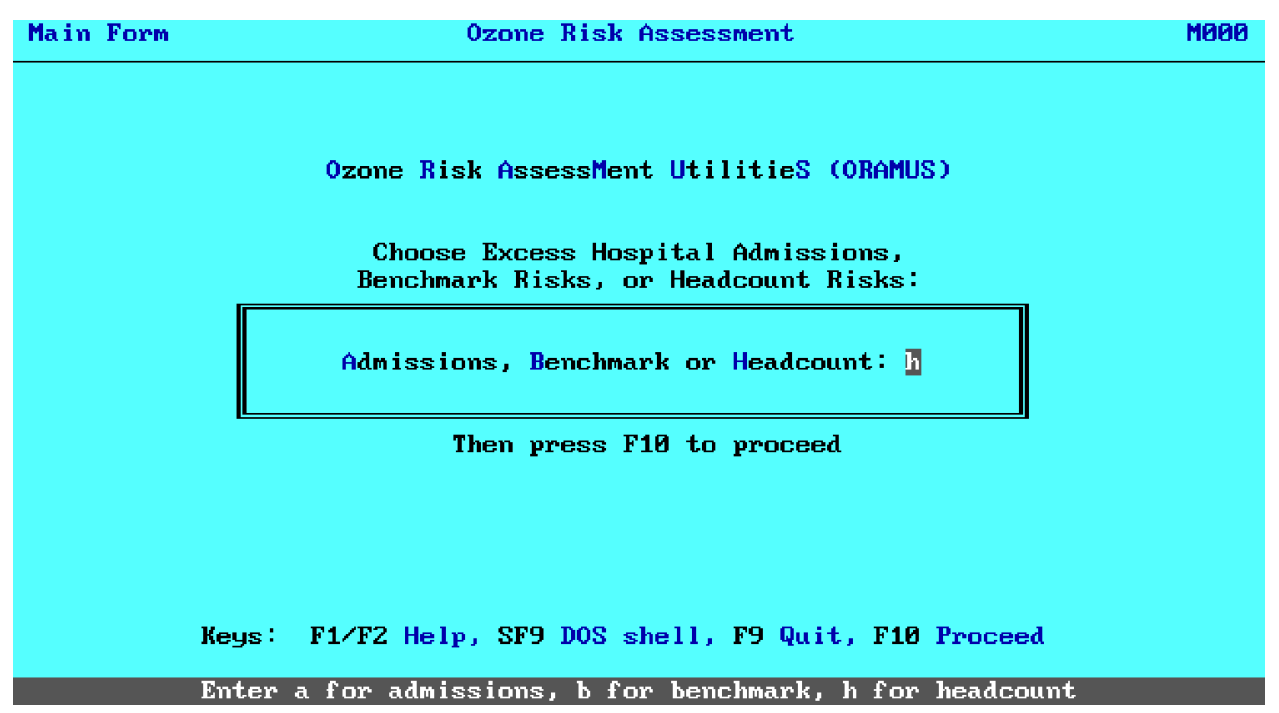

M000 - Main Form for ORAMUS

Using Forms. The user interface for ORAMUS consists of a set of forms used to (a) make branching choices, (b) enter text strings (e.g., a graph title), or (c) select one or more items from a list (e.g., select Chicago from a list of urban areas). While some forms have a large number (more than 100) of display-only and user-accessible areas (called fields), others have only one user-accessible field, which is usually one character wide.

Each form contains a title at the top and one or more fields in which you must input information. Each form also has a listing of function keys that perform special actions. The line at the bottom of the form gives an instruction specific to the current field. In most cases, you can press Esc to return to the previous form. Pressing F10 proceeds to the next step after you have input any necessary data in a form.

Before continuing with the tutorial, it is useful to become familiar with the help features built into ORAMUS. From Form M000, you can access Help screens by using the following keystrokes:

$<$ Press F1 to obtain general help for forms. You can also press F2 for form-specific help. The first Help screen provides information about the keystrokes used to move about the forms. 
$<$ Press F1 twice in any form to see a Help screen that shows the colors selected for the forms.

$<$ In any of these Help screens, press Esc to return to Form M000. The screens associated with these actions are shown on page 14 .

A schematic, which lists the components that make up the ORAMUS system, is shown in Table 2. Formats of principal input and output files are discussed in Appendix A.

Batch Files. As you become familiar with ORAMUS, you will learn that it runs from a series of batch files. As branching decisions are made, additional commands are appended to executing batch files to control more operations. The principal batch files are:

$\begin{array}{ll}\text { ORAMUS.BAT } & \text { STARTER.BAT } \\ \text { NEXT.BAT } & \text { GENEXT.BAT } \\ \text { GOHCBOX.BAT } & \text { GNEXTINI.BAT }\end{array}$




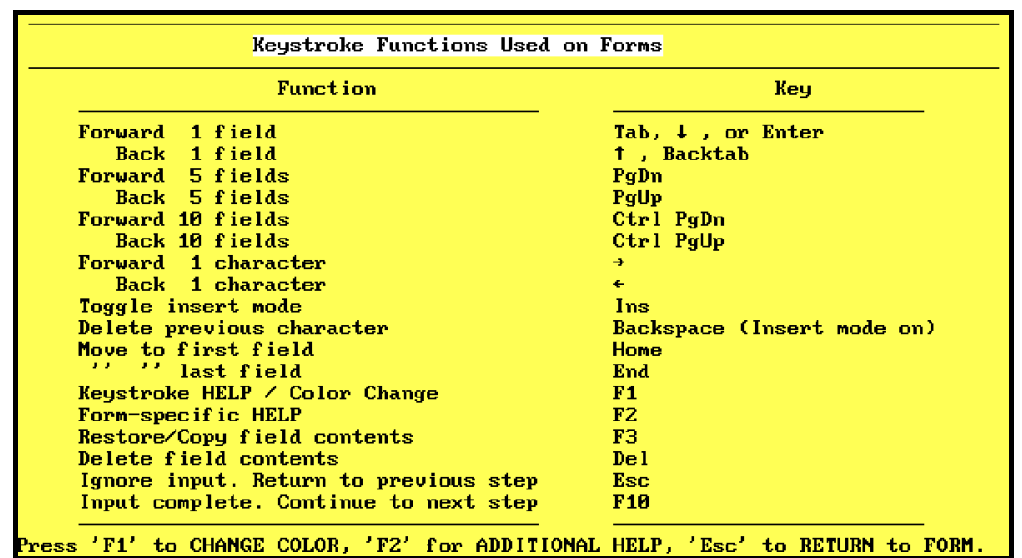

Keystrokes for Moving around in Forms (obtained by pressing $\mathrm{F} 1$ )

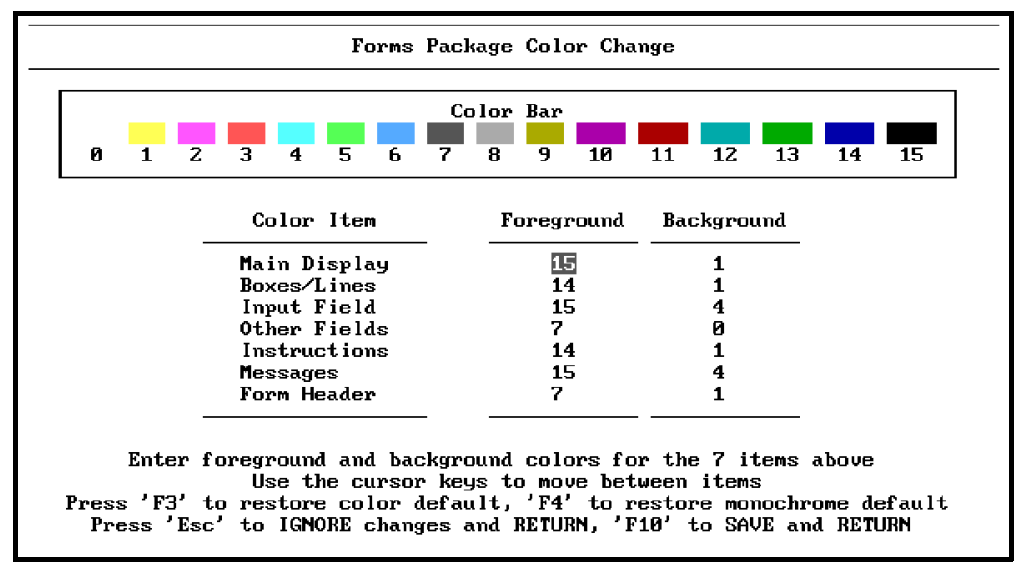

Screen Colors for Forms (obtained by pressing F1 twice)

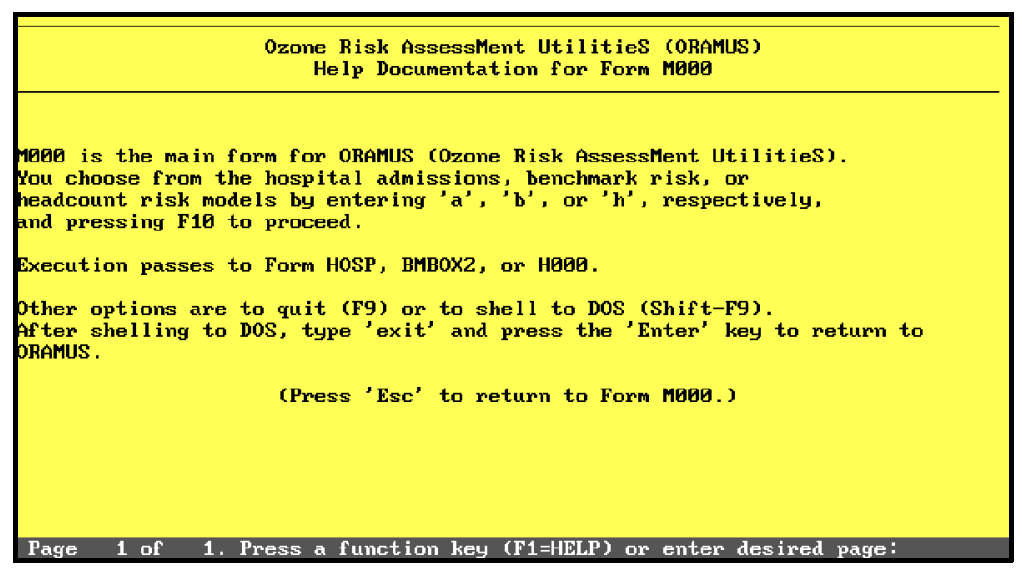

Example of Help Documentation for ORAMUS Forms

(obtained by pressing F2 in Form M000) 


\section{TABLE 2 Schematic for ORAMUS}

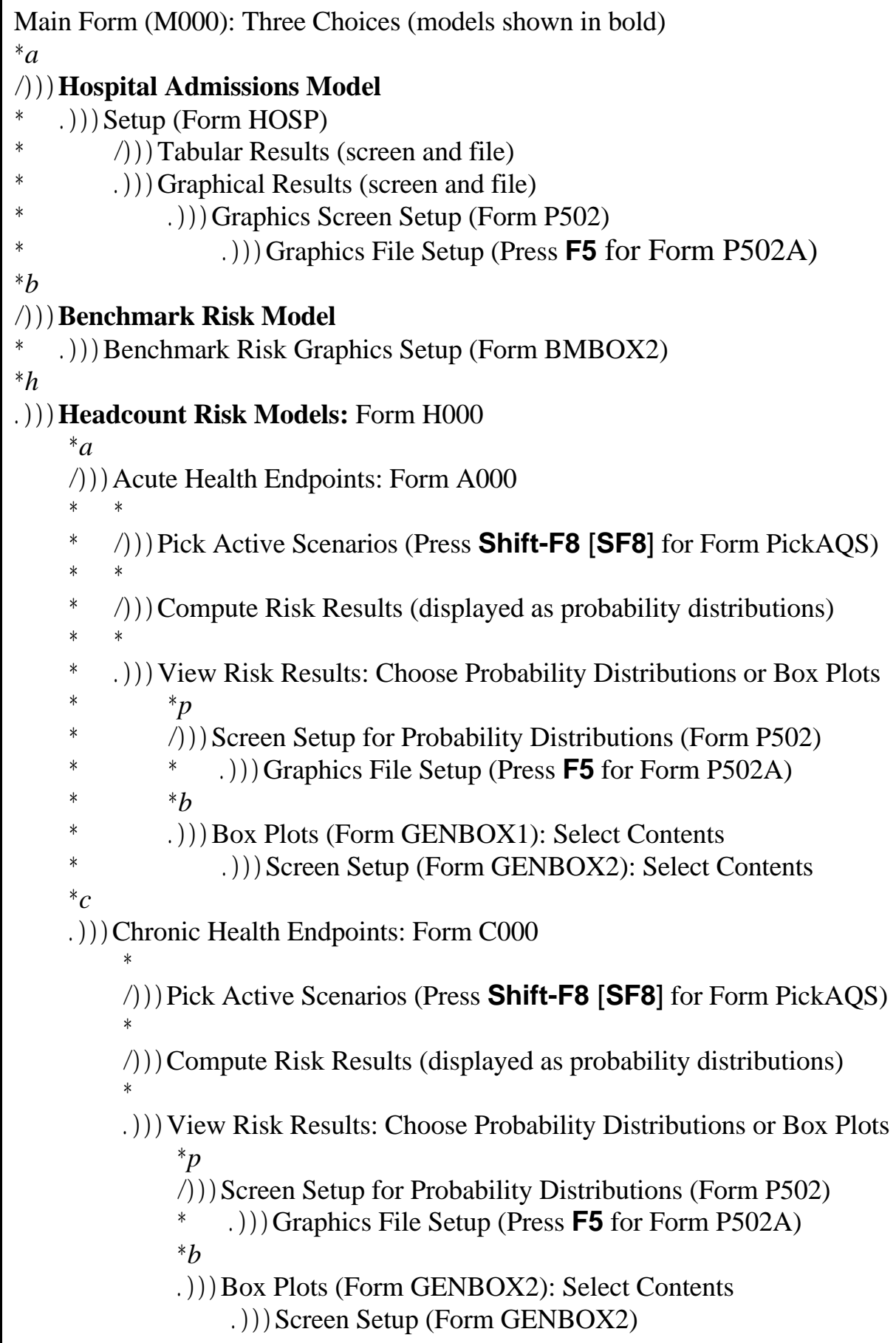


To proceed with the tutorial,

1. In Form M000 (shown on page 12), Type $\mathbf{h}$ (for headcount risks). (Note: all entries are case insensitive throughout the program.)

2. To display Form H000 (shown below), press F10 (or Enter). Form H000 is used to select acute or chronic headcount risk models. Headcount risks for acute health endpoints are discussed in Section 4. Chronic risks are discussed in Volume 2.

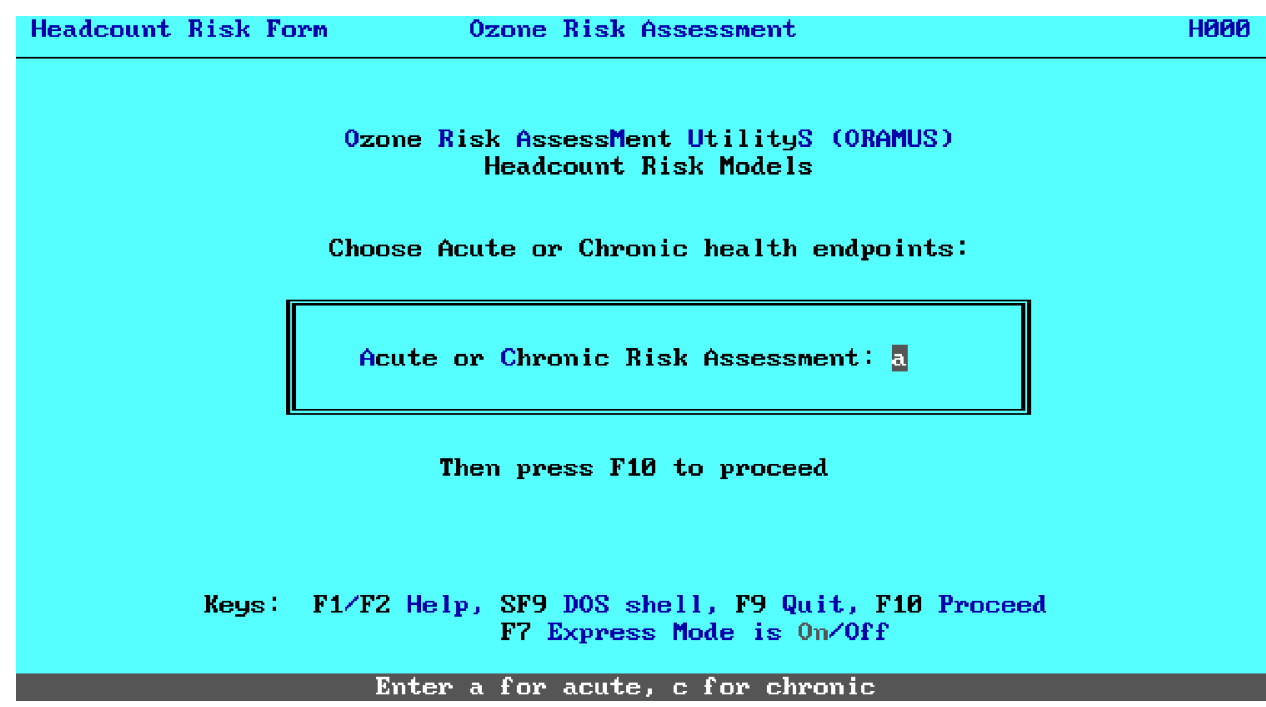

H000 - Main Form for Headcount Risk Models 


\section{HEADCOUNT RISKS FOR ACUTE ENDPOINTS}

Headcount risk looks at the number of persons affected and the number of incidences of a given health effect. This measure takes into account exposures to individuals as they go about their daily activities (e.g., going from indoors to outdoors, moving from place to place, and engaging in activities at different levels of exertion).

\section{Choosing between Acute and Chronic Health Endpoints}

ORAMUS allows you to work with either acute or chronic health endpoints. Acute health endpoints, such as lung function and symptoms, are associated with short-term (1- to 8-hour) exposures to ozone. Chronic health endpoints are associated with long-term ( 1 or 10 seasons) exposures.

You have already selected $\mathbf{h}$ in Form M000 to reach Form H000, the Headcount Risk Form. The tutorial continues with an example for acute health endpoints (the alternate choice is for chronic health endpoints, which is discussed in Volume 2).

1. In Form H000, type a (for acute risks).

2. To display Form A000, press F10 (or Enter). This form is the main form used for viewing or computing selected results for acute health endpoints.

Express Mode. A useful key in Form H000 is F7, which toggles the express mode on and off. The default mode is off. (Note the color change in the words "On" and "Off" to indicate the express mode.) The express mode allows you to skip intermediate screens associated with viewing the results as probability distributions. Details on viewing probability distributions are provided later in this section. 


\section{Computing Selected Risk Results for Acute Health Endpoints}

Form A000 is the main screen used for selecting urban areas, health endpoints, air quality scenarios, populations, and types of exposure measure (persons or [person]-occurrences) for which acute risk results are to be viewed and computed. These items are organized into five sections. If you need complete risk results, you should compute them in large blocks, as indicated on page 18 of Form A000.

Health Endpoint Names. A strict naming convention is used for risk output files. You are not at liberty to change file names; doing so would produce undesirable results. You do not have to be concerned with this matter because ORAMUS creates and names all risk output files. You need only understand the meaning of the names. The file naming conventions for acute health endpoints are fully explained later in this section.

The first character in the health endpoint name indicates the human exposure study upon which the endpoint is based. Characters $2-4$ denote the health endpoint. The last character in the health endpoint name indicates exposure characteristics: 1 denotes a 1-hour exposure at heavy exertion, 2 denotes a 1-hour exposure at moderate exertion, and 8 denotes an 8-hour exposure at moderate exertion. Appendix B gives a complete listing of the health endpoints and supporting human exposure studies.

In Form A000, selected items are marked with an asterisk. These items are all urban areas and all listed air quality scenarios; all health endpoints that end with a " 1 (the box above provides information about health endpoint names; if you select more than one endpoint, all names must end with the same number [i.e., 1, 2, or 8]); children (only one population group at a time may be selected); and "p" (persons or [person]-occurrences).

$<$ To include (mark) an item, press F4. Doing so places an asterisk in the field and advances to the next field.

$<$ To exclude (unmark) an item, press F5. Doing so places a blank in the field and advances to the next field. 
$<$ To clear all marks, press Shift-F4 (SF4).

$<$ To move to the next section, press F6.

$<$ To open a DOS shell, press Shift-F9 (SF9).

$<$ To return to Form H000, press F9.

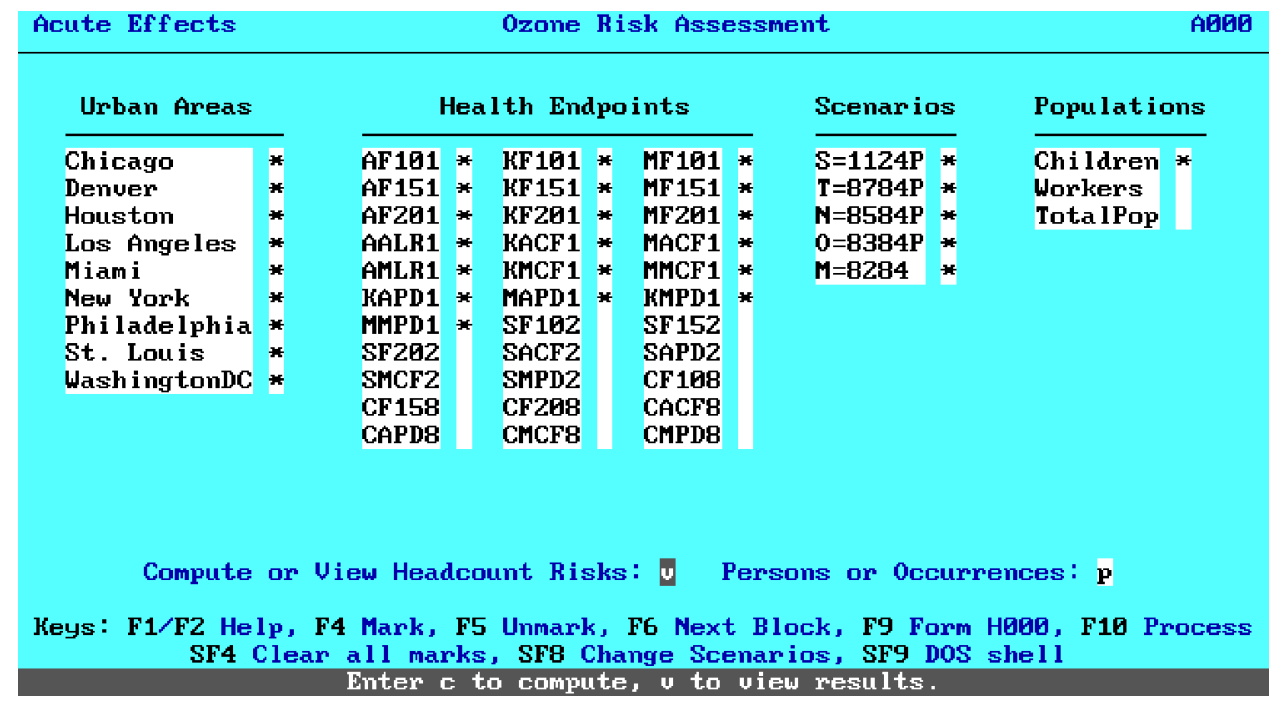

A000 - Setup Form for Computing or Viewing Risk Results for Acute Health Endpoints

Continue to follow the instructions below to shorten the run time for the compute step.

1. Press Shift-F4 (SF4) to clear all marks.

2. In the "Urban Areas" section, mark Houston, Los Angeles, New York, Philadelphia, St. Louis, and Washington, D.C.

3. In the "Health Endpoints" section, mark MMCF1. (You can press PgDn or Ctrl-PgDn to move 5 or 10 fields, respectively, to quickly reach the field for MMCF1.) This health endpoint name stands for moderate-to-severe cough, based on the data of McDonnell et al. (1983). A complete listing of the human exposure studies, which form the basis for acute health endpoints that can be analyzed with ORAMUS, is provided in Appendix B. 
4. To locate the "Scenarios" section, press F6.

5. In the "Scenarios" section, mark all four scenarios $\mathrm{S}, \mathrm{T}, \mathrm{N}$, and $\mathrm{O}$.

6. In the "Populations" section, mark Children.

7. To specify computing risks, press F6 and type $\mathbf{c}$.

8. Press Enter.

9. Type $\mathbf{p}$ to specify the persons measure. Form A000 should now display the data in the screen shown below.

10.

Press F10 to begin to compute results for the selections you made.

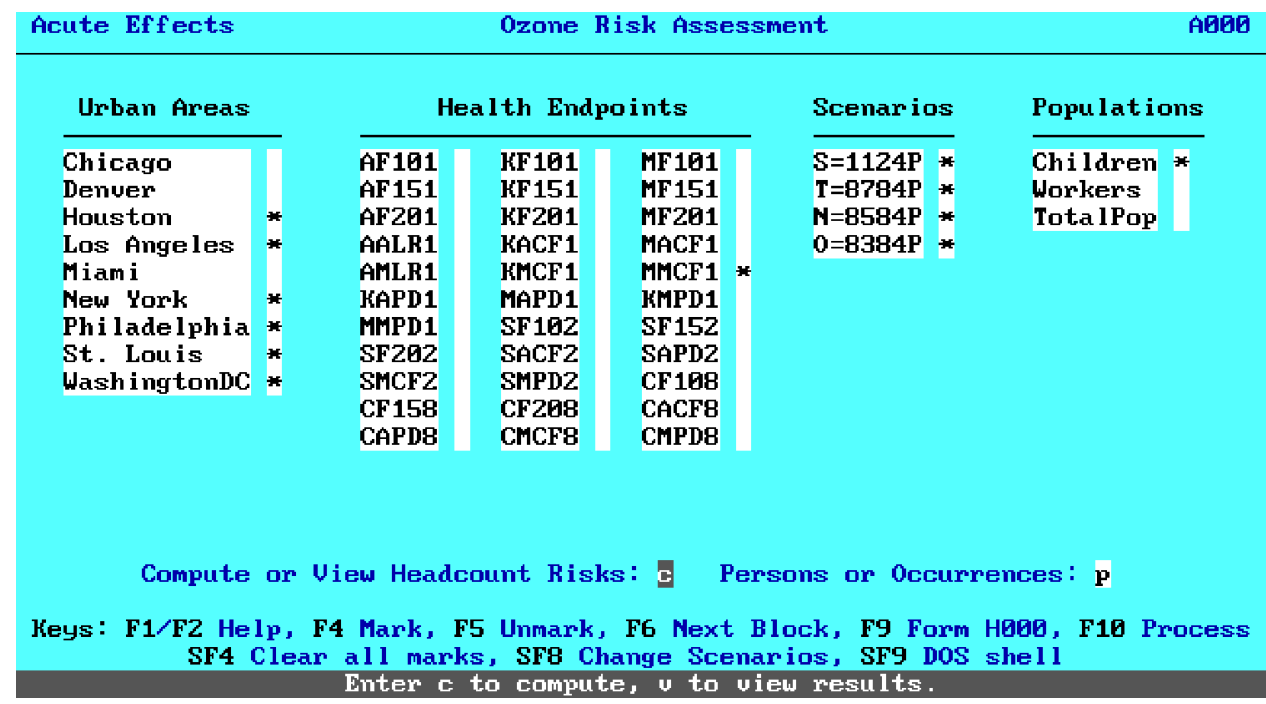

A000 - Setup Form for Computing Selected Risk Results for Acute Health Endpoints

Several DOS messages are displayed (giving you the names of input and output files). A message then notifies you that no graphics can be produced because more than one item has been marked in two or more sections, which makes it impossible to produce graphics. The program then returns to Form A000. 


\section{Directory Structure and File Naming Conventions}

Under the ORAMUS directory, results for 1-hour exposures at heavy exertion health endpoints are written in the 1HR directory; results for 1-hour exposures at moderate exertion health endpoints are written in the 2HR directory; and results for 8-hour exposures at moderate exertion health endpoints are written in the $8 \mathrm{HR}$ directory. In addition, results for chronic health endpoints are written in the CHRONIC directory; results for hospital admissions are written in the HOSPITAL directory; and benchmark risk results are stored in the BENCHMRK directory. The naming conventions for acute risk output file specifications are listed in Table 3.

\section{TABLE 3 File Naming Conventions for Acute Health Endpoints}

\begin{tabular}{|c|c|c|}
\hline $\begin{array}{l}\text { Character } \\
\text { Position }\end{array}$ & Significance & Example \\
\hline \multicolumn{3}{|l|}{ Filename } \\
\hline 1 & $\begin{array}{l}\text { Human exposure } \\
\text { study }\end{array}$ & $\begin{array}{l}\text { A for Avol, } \mathrm{K} \text { for Kulle, } \mathrm{M} \text { for McDonnell, } \\
\mathrm{S} \text { for Seal, } \mathrm{C} \text { for combined (Horstman et al., } \\
\text { Folinsbee et al., and McDonnell et al.) }\end{array}$ \\
\hline $2-4$ & Health endpoint & $\begin{array}{l}\text { F10 for } \mathrm{FEV}_{1} \text { decrement } \$ 10 \%, \mathrm{ACF} \text { for any } \\
\text { cough, MPD for moderate-to-severe chest pain, } \\
\text { ALR for any lower respiratory symptom, and } \\
\text { so on }\end{array}$ \\
\hline 5 & $\begin{array}{l}\text { Exposure time, } \\
\text { exertion level }\end{array}$ & $\begin{array}{l}1 \text { for } 1 \text { hour at heavy exertion, } 2 \text { for } 1 \text { hour at } \\
\text { moderate exertion, and } 8 \text { for } 8 \text { hours at } \\
\text { moderate exertion }\end{array}$ \\
\hline 6 & Urban area & $\mathrm{C}$ for Chicago, $\mathrm{L}$ for Los Angeles, and so on \\
\hline 7 & Population & $\begin{array}{l}\mathrm{C} \text { for outdoor children, } \mathrm{W} \text { for outdoor workers, } \\
\text { and } \mathrm{T} \text { for total population }\end{array}$ \\
\hline 8 & $\begin{array}{l}\text { Air quality } \\
\text { scenario }\end{array}$ & $\begin{array}{l}\mathrm{Z} \text { for As-Is; A for } 1 \text { hour, } 1 \text { expected } \\
\text { exceedance, } 0.12 \text { ppm of ozone; } \mathrm{V} \text { for } 8 \text { hours, } \\
\text { seventh highest maximum, } 0.084 \text { ppm of } \\
\text { ozone, Weibull rollback; etc. }\end{array}$ \\
\hline \multicolumn{3}{|l|}{ Extension } \\
\hline 1 & Headcount & $\mathrm{H}$ (required) \\
\hline 2 & Risk measure & $\mathrm{P}$ for persons and $\mathrm{O}$ for person-occurrences \\
\hline 3 & Risk & $\mathrm{R}$ (required) \\
\hline
\end{tabular}




\section{Specifying Active Air Quality Scenarios}

Although only 5 scenarios are shown in Form A000, you can select from as many as 10. Limiting the maximum number of "active" scenarios to 10 is necessary to produce readable graphs. To specify which scenarios are active, follow these steps:

1. Press Shift-F8 (SF8) to display Form PickAQS (shown below).

2. For practice, unmark Scenario M (by pressing CursorUp [8], CursorUp, F5) and press F10.

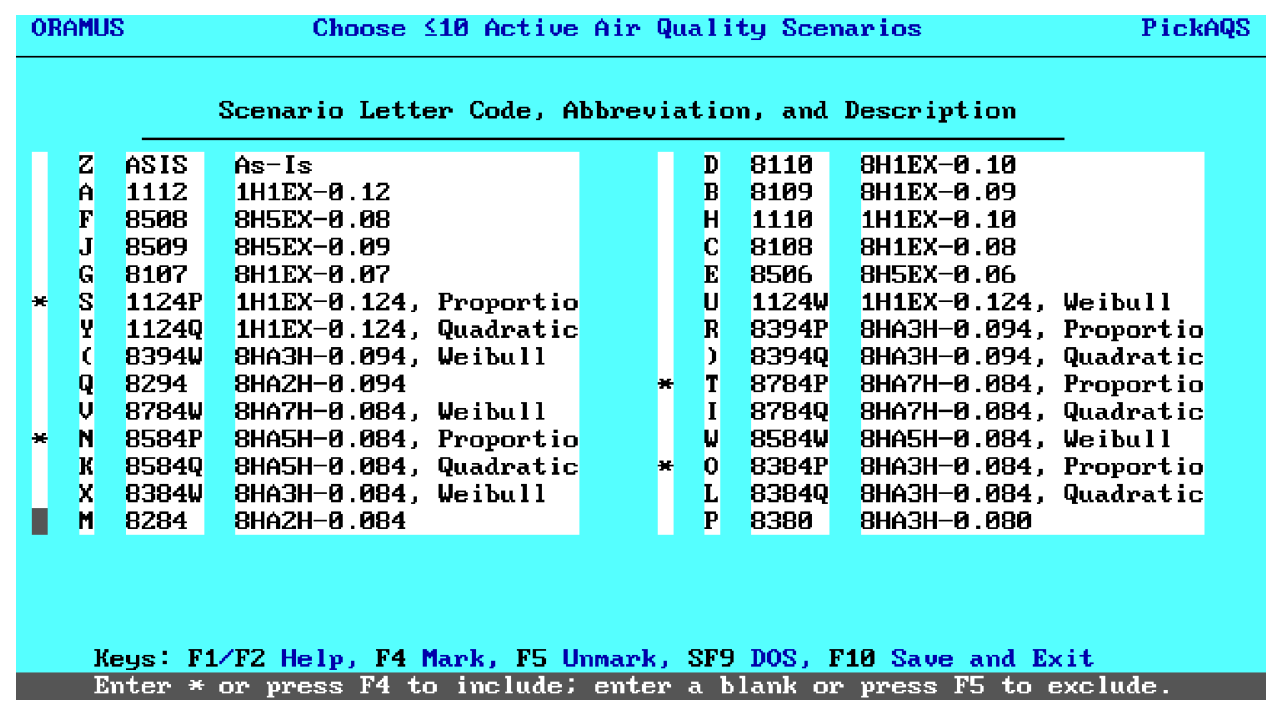

PickAQS - Form for Selecting Active Air Quality Scenarios

After a series of DOS commands has been completed, Form A000 is again displayed. Scenario $M$ is not listed because you unmarked it in Form PickAQS. 
Scenario Information. A total of 27 scenarios are available for acute health endpoints: 26 alternative NAAQS and 1 scenario that represents current (As-Is) air quality for 1990 or 1991 (i.e., the data for a specific urban area are either 1990 or 1991 data). Your choices, which are saved in the file PickAQS.sav, are in effect for computing or viewing headcount risks and hospital admissions.

Pressing F10 in Form PickAQS executes the DOS ATTRIB command, which hides risk output files for unmarked air quality scenarios and "unhides" files for marked scenarios. Consequently, to compute risk results for all 27 scenarios for a particular group of health endpoints, you need a minimum of three selection steps and subsequent computation steps for each population. It is most efficient to compute risk results for all allowable combinations of urban areas, health endpoints, populations of interest, and exposure types before changing the scenario set. The program returns to, in this case, Form A000. You can also access Form PickAQS from Form C000, Form HOSP, and DOS.

\section{Viewing Risk Results as Probability Distributions}

To continue with the tutorial, perform the following steps:

1. Unmark all urban areas, except Philadelphia.

2. Press F6 four times.

3. Type $\mathbf{v}$ to view.

4. Press F10 to proceed. You will notice a pause - indicated by a beep tone - after setup information is displayed. To terminate this (or any) pause and continue, press any key.

5. Once you have terminated the display of setup information, you can choose to view the output either as probability distributions or as box plots (Form PorB).

6. To select probability distributions, type $\mathbf{p}$. 
7. Press F10 to proceed. Statistics about the risk distributions are displayed for each air quality scenario.

8. Press any key to see a list of selected air quality scenarios; you must choose one scenario as a reference. It is often desirable to choose the scenario associated with the largest risks as your reference scenario.

9. To choose $1124 \mathrm{P}$ as the reference scenario, type 1.

10.

To display a graph of risk distributions, press Enter.

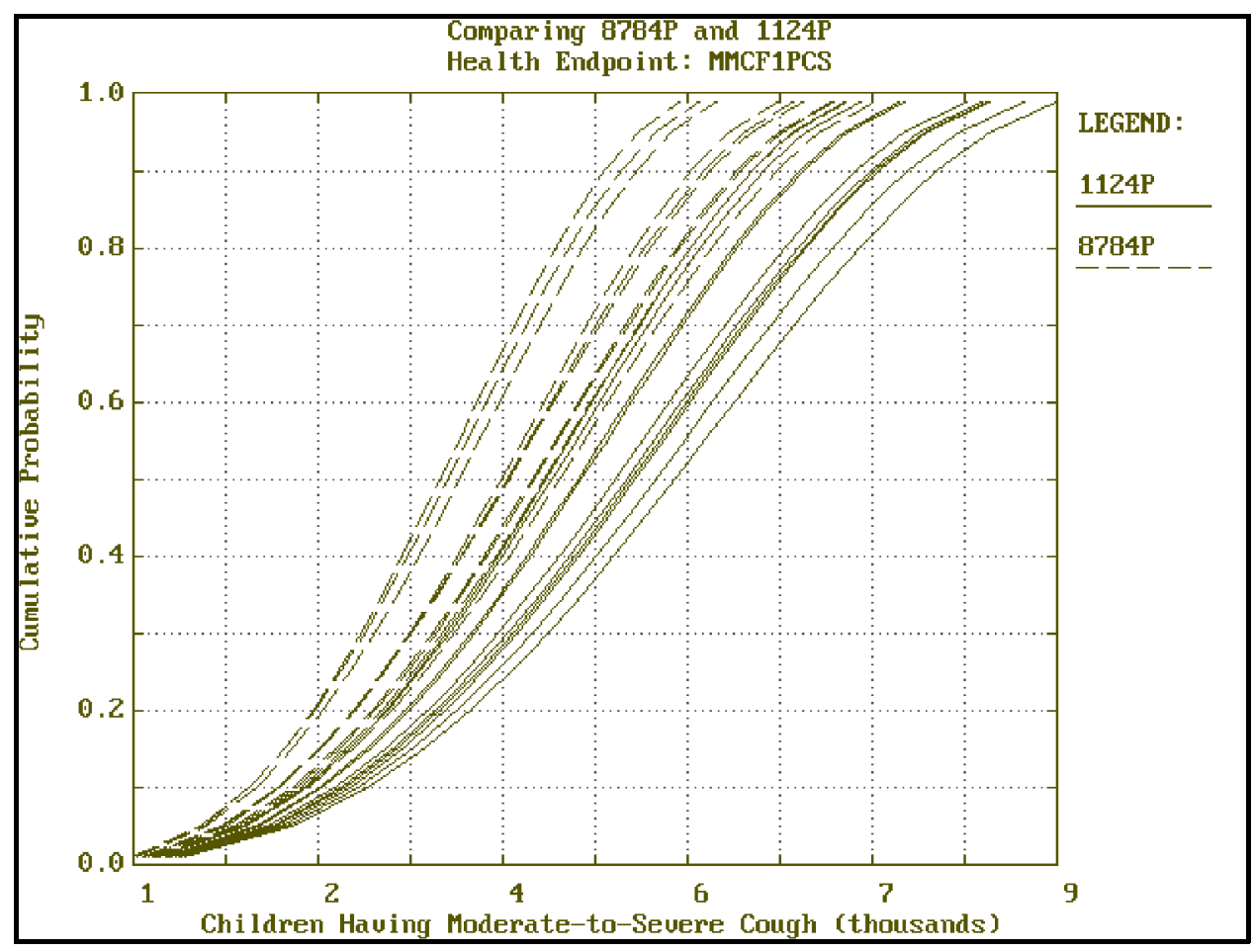

A Set of 10 Risk Distributions for Each of 2 Air Quality Scenarios 
Graphs. The screen displayed on page 24 is a graph of two sets of probability distributions over the number of children who may experience moderate-to-severe cough after 1-hour exposures to ozone at heavy exertion. (Note: press F1 or F2 for help. The grid lines can be toggled on and off by repeatedly pressing $\mathbf{g}$.) Each set has 10 probability distributions because there are $10 \mathrm{pNEM} / \mathrm{O}_{3}$ runs for each air quality scenario. There is one set for each of two air quality scenarios. In the current example, variability occurs among runs, which is indicated by the spacing between the 10 distributions in each set.

The tutorial now moves forward to the next form, which allows you to modify the axes.

1. To proceed to Form P502, press any key. In this form, you can modify the $\mathrm{X}$ - and $\mathrm{Y}$-axes.

2. To regraph the data, press F9. Note the improvement in the $\mathrm{X}$-axis format. Press any key to return to Form P502. Use the up/down arrows to move to the required boxes. Modify the values to those displayed in Form P502 (see below).

3. To proceed to the next graph, press F10. For the current example, two more graphs will follow, which will complete the three possible comparisons of the reference scenario to the remaining selected scenarios.

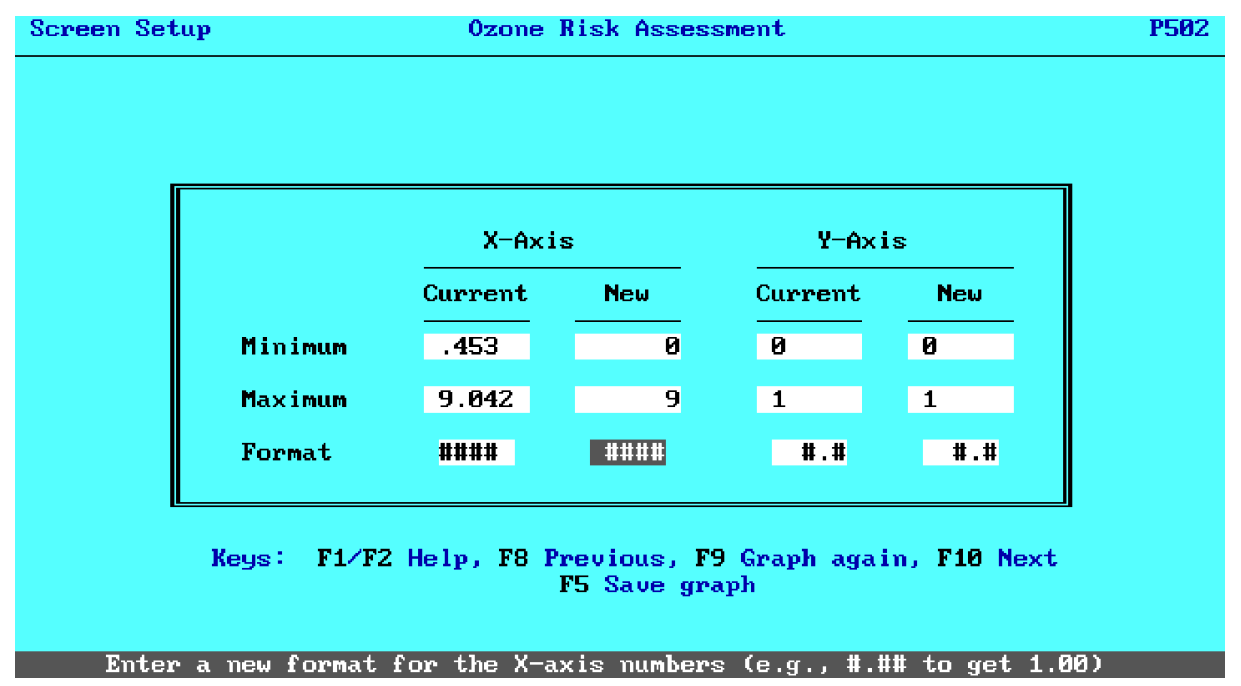

P502 — Form for Controlling Graph Properties 


\section{Representative Distributions and Vector Graphics Images}

After all comparisons with the reference scenario have been displayed, a figure with one distribution that is "representative" of each set of 10 distributions is displayed.

To create a vector graphics data file for this graph, proceed as follows:

1. To display Form P502, press any key.

2. Press F5 to start the process of saving the data (in an ASCII file) to later create a vector graphics data file (in WordPerfect Graphics [WPG] format).

3. After a pause during which data for the graph are displayed, press any key to display Form P502A. Modify the values as shown in the form below. You can specify titles, axis labels, data ranges, formats, and an output filename.

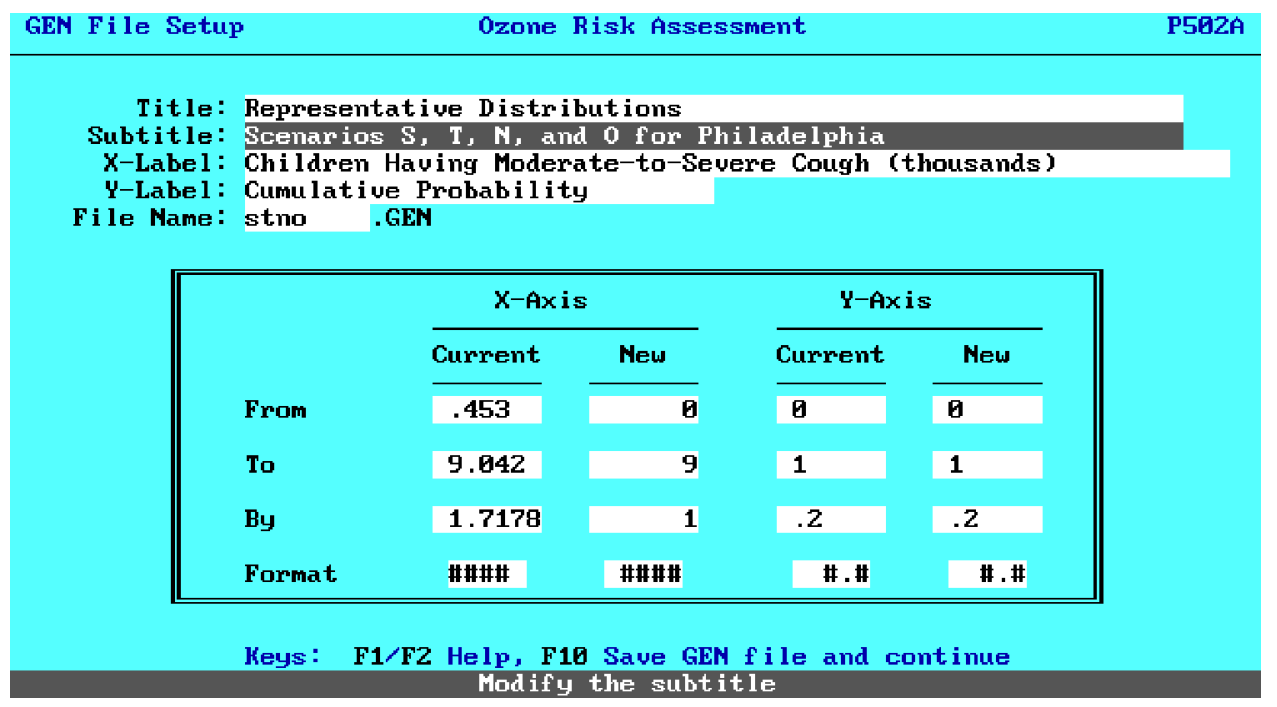

P502A — Form for Controlling Properties of a WordPerfect Graphics Image

4. Press F10 to save the vector graphics data file and then display another graph showing the differences between the reference scenario and the other scenarios. 
Because of memory limitations, it is not possible to create the vector graphics data file while ORAMUS is running (unless you are running under Windows). After you exit ORAMUS, you can create vector graphics data files (in WPG format), as discussed later.

WPG Files. The figure shown below is an example WPG image that can be created by using ORAMUS and GEN.EXE. For more information on using GEN.EXE, see the user's guide (Jusko and Whitfield 1996) included on the installation disk (GENPLOT.W51, a WordPerfect 5.1 document) or the discussion on pages 32 and 33.

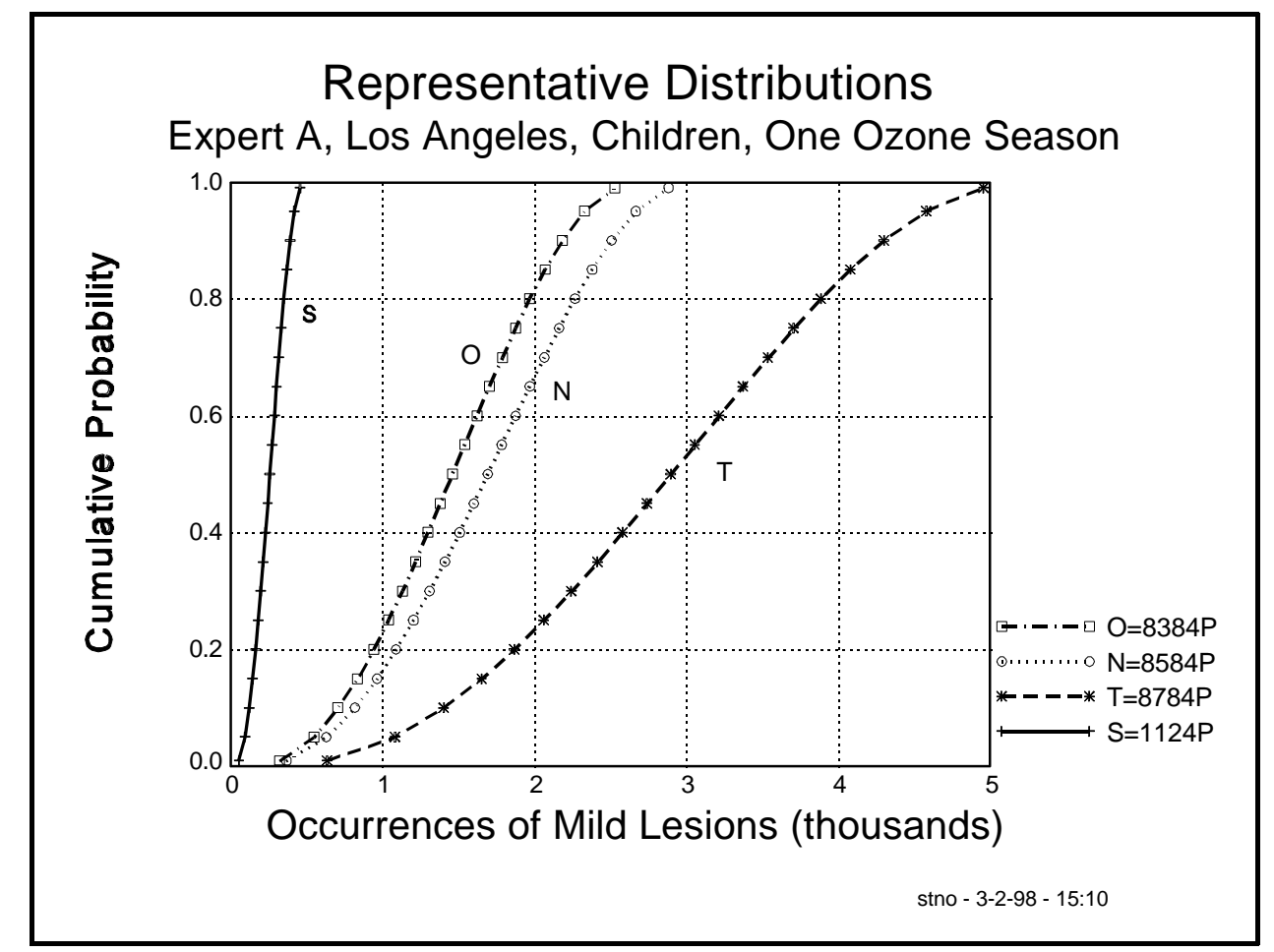

Example of a WordPerfect Graphics Image 


\section{Differences between the Reference Scenario and Other Scenarios}

After saving the graphics data or simply viewing the screen that shows the representative distributions, ORAMUS displays a screen (shown below) that shows the differences between the reference representative risk distribution and the other distributions. These differences are displayed as probability distributions. Exiting the screen setup form that follows this graph returns you to Form A000.

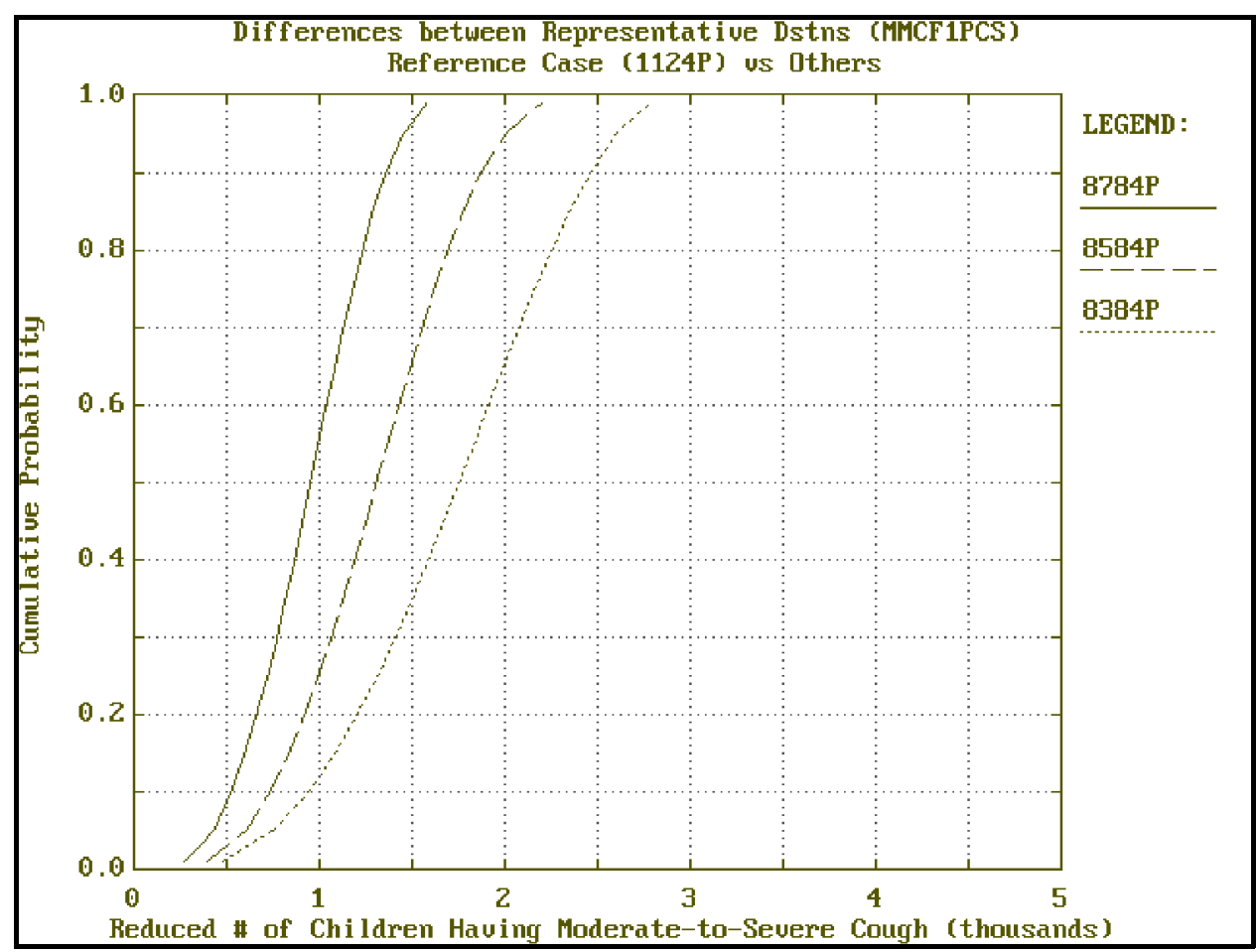

Differences between the Reference Representative Distribution and Other Distributions 


\section{Viewing Risk Results in Box Plot Format}

This portion of the tutorial takes you through the steps needed to view the risk results as box plots rather than as probability distributions.

1. Return to Form A000. The settings for viewing the results should still be displayed. Press F10 to display selection information, which is followed by a pause.

2. Press any key to end the pause and display Form PorB.

3. Type $\mathbf{b}$ for box plots and press F10.

Box Plots. It is important at this time to note a critical constraint on box plot graphs. The number of output files must exactly match the number of urban areas times the number of air quality scenarios. In the current example, this requirement is met.

Four scenarios are active (S, T, N, and $\mathrm{O})$. All have abbreviations that end in the letter $\mathrm{P}$, meaning that results can be computed for proportional, Weibull, and quadratic air quality adjustment procedures. Some abbreviations (e.g., 8284, which you removed from consideration in Form PickAQS) do not end with the letter P, meaning that results are not available for Weibull or quadratic air quality adjustment procedures. For reasons beyond the scope of this manual, there are no Weibull or quadratic exposure estimates for three urban areas (Chicago, Denver, and Miami). Furthermore, there are no Weibull or quadratic exposure estimates for the "earlier" air quality scenarios. Therefore, attempts to display box plots for scenarios that have "complete" results (i.e., for all three air quality adjustment procedures) with those that do not have complete results will fail if data are "missing." If you follow the instructions for specifying active air quality scenarios (given on page 22), you can avoid this pitfall. 
4. Type $y$ to acknowledge that you want to view/change the active air quality scenarios. Pressing $\mathbf{y}$ automatically takes you to Form PickAQS.

5. If Scenario $M=8284$ is still active (it should not be active if you have been following the tutorial), remove it (i.e., unmark it) from the active list and press F10. Wait until a series of DOS commands are executed and Form GENBOX1 is displayed. (These commands hide "unwanted" air quality scenarios by using the DOS ATTRIB command.) If Scenario M is not active, press Esc to display Form GENBOX1.

6. Modify the fields in Form GENBOX1 as indicated in the screen below.

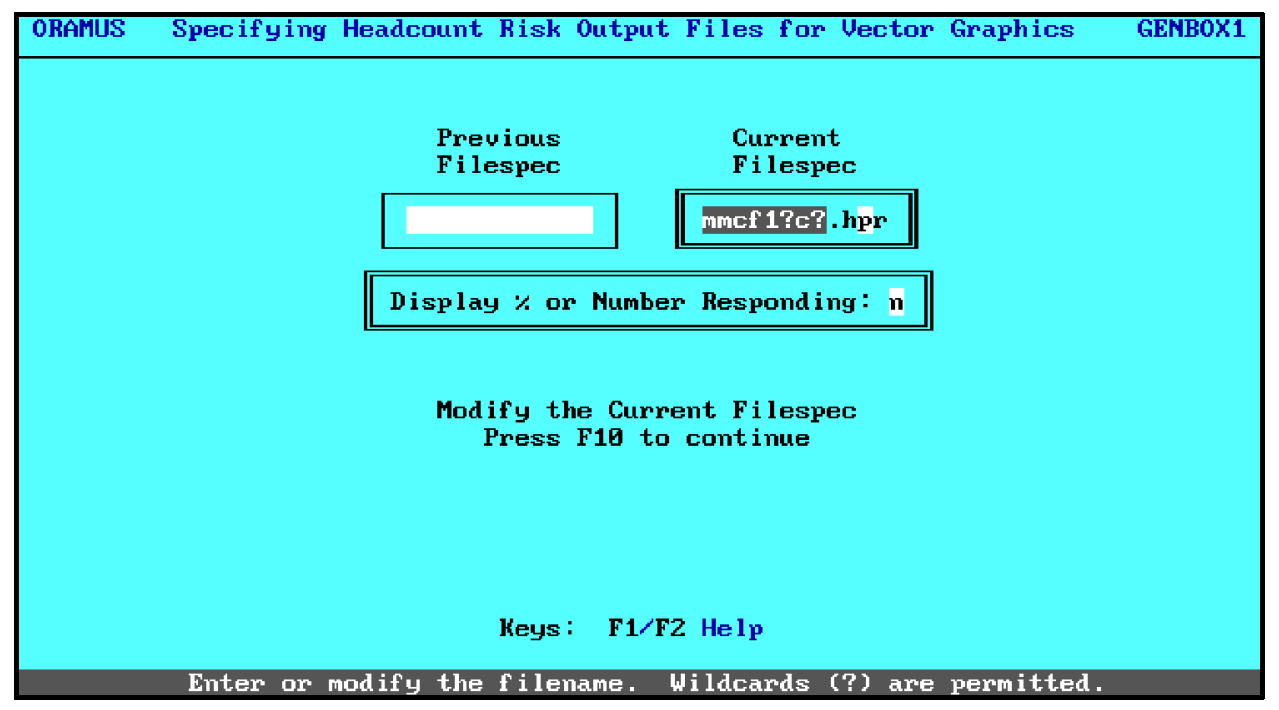

GENBOX1 - Form for Specifying the Contents of a Box Plot 
Discussion. In Form GENBOX1, the entries in the Current Filespec box specify that the graph will include results based on the human exposure studies conducted by McDonnell et al. (1983) (indicated by the leading letter M) for moderate-to-severe cough (MCF), 1-hour exposures at heavy exertion, all urban areas (indicated by the first question mark; in this case, six urban areas will be included), outdoor children (indicated by the second $\mathrm{C}$ ), and all active air quality scenarios (indicated by the second question mark; in this case, four scenarios will be included). The $p$ in the extension $h p r$ means to include results for the persons measure (rather than person-occurrences). The $N$ in the "Display" field means to display results in terms of the number of children responding (rather than percent responding).

7. To proceed to a graph setup screen (Form GENBOX2), press F10.

8. Enter the data indicated in Form GENBOX2 shown below. The key modifications to make in the section labeled "New" are to change the units to $\mathbf{k}$ for thousands and change the "to" and "by" values to $\mathbf{1 8}$ and $\mathbf{2}$, respectively. These changes result in a graph that is easier to read. The box plot (a vector graphics image) is shown on the next page.

9. To proceed to the box plot, press F10.

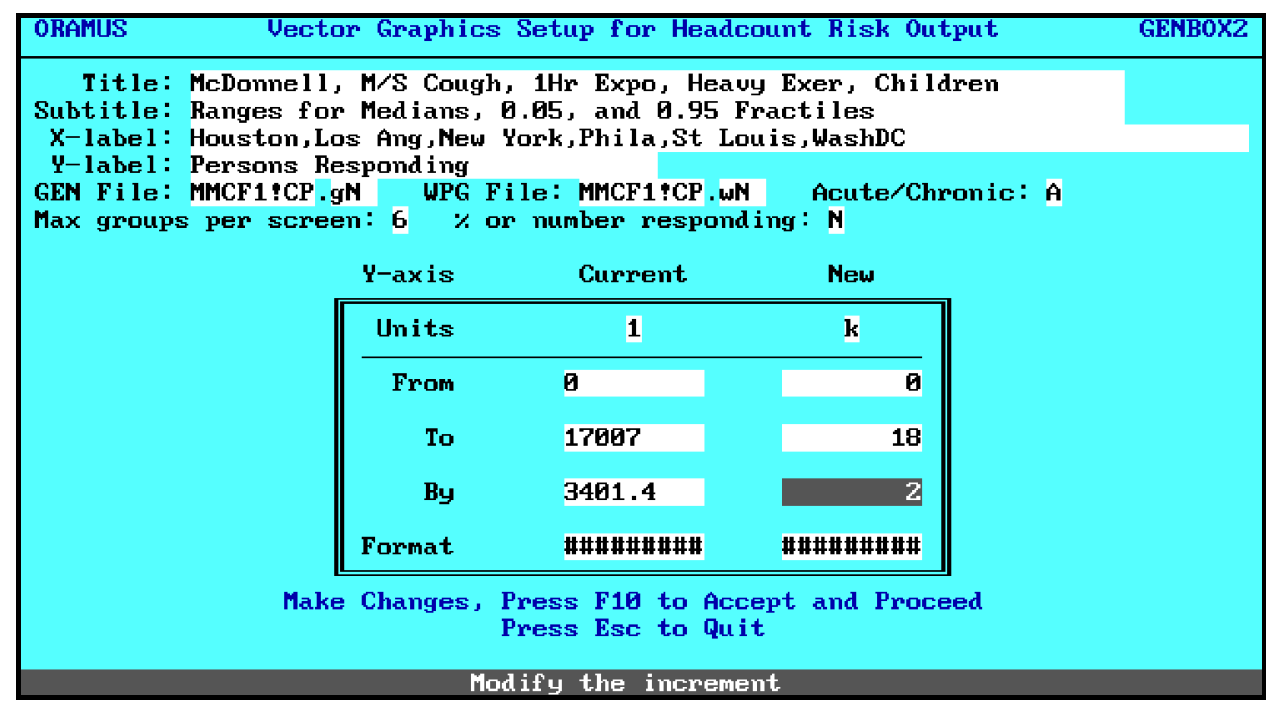

GENBOX2 - Form for Specifying the Appearance of the Box Plot 


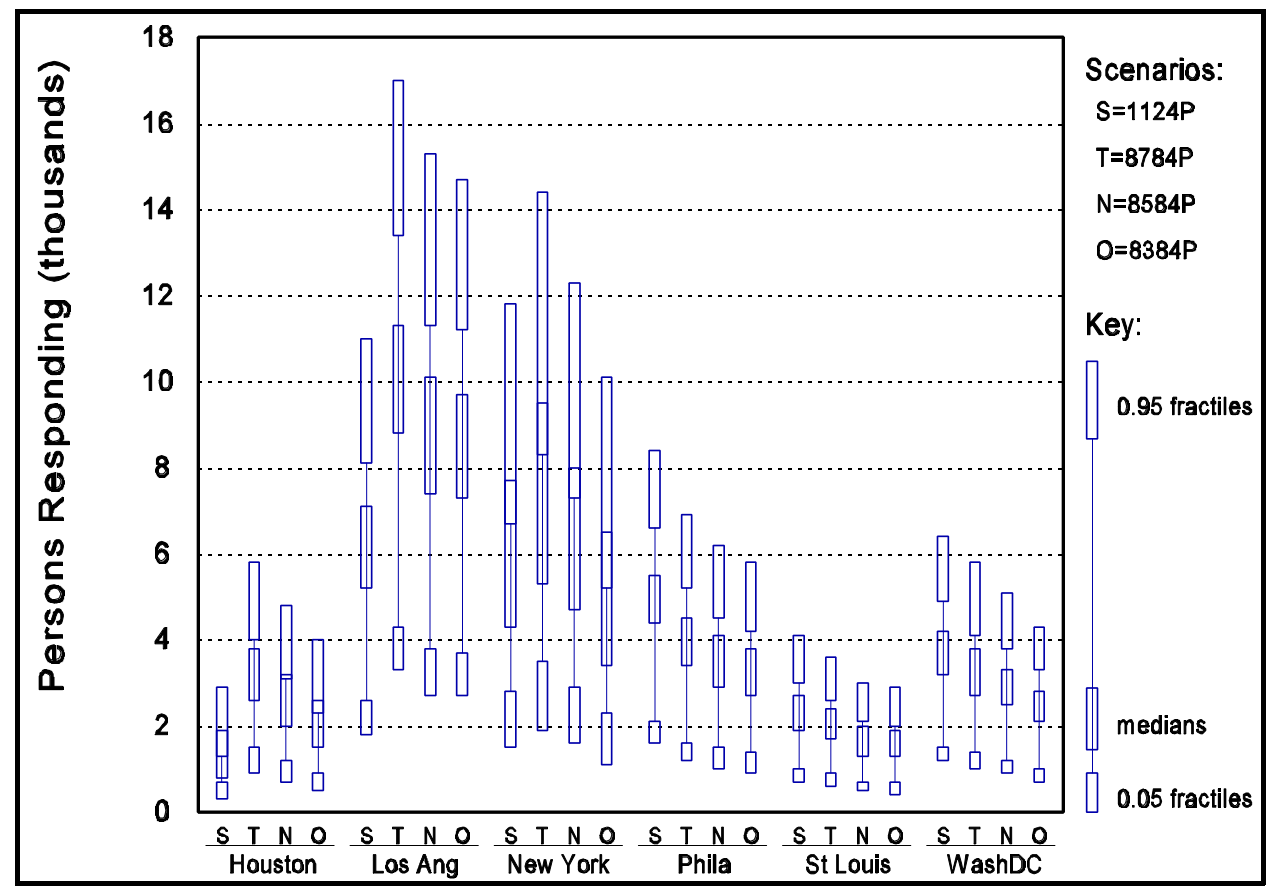

Vector Graphics Image of the Box Plot Format for Acute Risk Results (children, moderate-to-severe cough, 1-hour exposures at heavy exertion, based on McDonnell et al. 1983)

\section{Creating a Vector Graphics Image File}

If you are running ORAMUS under DOS, you must create a vector graphics image file while ORAMUS is not running. To begin this process, exit ORAMUS. If you have been following the tutorial and Form A000 is displayed, press Esc four times to exit ORAMUS. (If you are running under Windows, you can continue to run ORAMUS if you open a new DOS window.)

In the ORAMUS directory, enter the following DOS commands:

1. cd 1hr.

2. ...gen stno.gen stno.wpg nul. 
The screen displays a figure that resembles the graph of representative distributions shown on page 27, which has been enhanced in a graphics editor (scenario code letters were added to identify each distribution, and the text "legend" was added to identify the legend). Note that the second parameter of the gen command is a file specification (stno.wpg); this file is a vector graphics image file that can be incorporated into a word processing document or modified in a graphics editor. The third parameter is reserved for the name of an HP Graphics Language (HPGL) file. In this case, no HPGL file was created because "nul" was specified. If you want to create an HPGL file, specify a legitimate file specification (e.g., stno.hpg). 


\section{HOSPITAL ADMISSIONS MODEL}

The hospital admissions model is based on (1) regression coefficients and corresponding standard errors developed by Thurston et al. (1992) and (2) 1-hour daily maximum ozone concentrations developed by Johnson et al. (1996a-c). The model applies only to New York City and includes two types of respiratory admissions: asthmatics and members of the general population (including asthmatics) for any of a number of respiratory ailments (i.e., acute bronchitis or bronchiolitis, pneumonia, or chronic obstructive pulmonary disease not related to asthma). To run the hospital admissions model, proceed as follows:

1. Type a (for admissions) in Form M000.

2. To display Form HOSP, press F10.

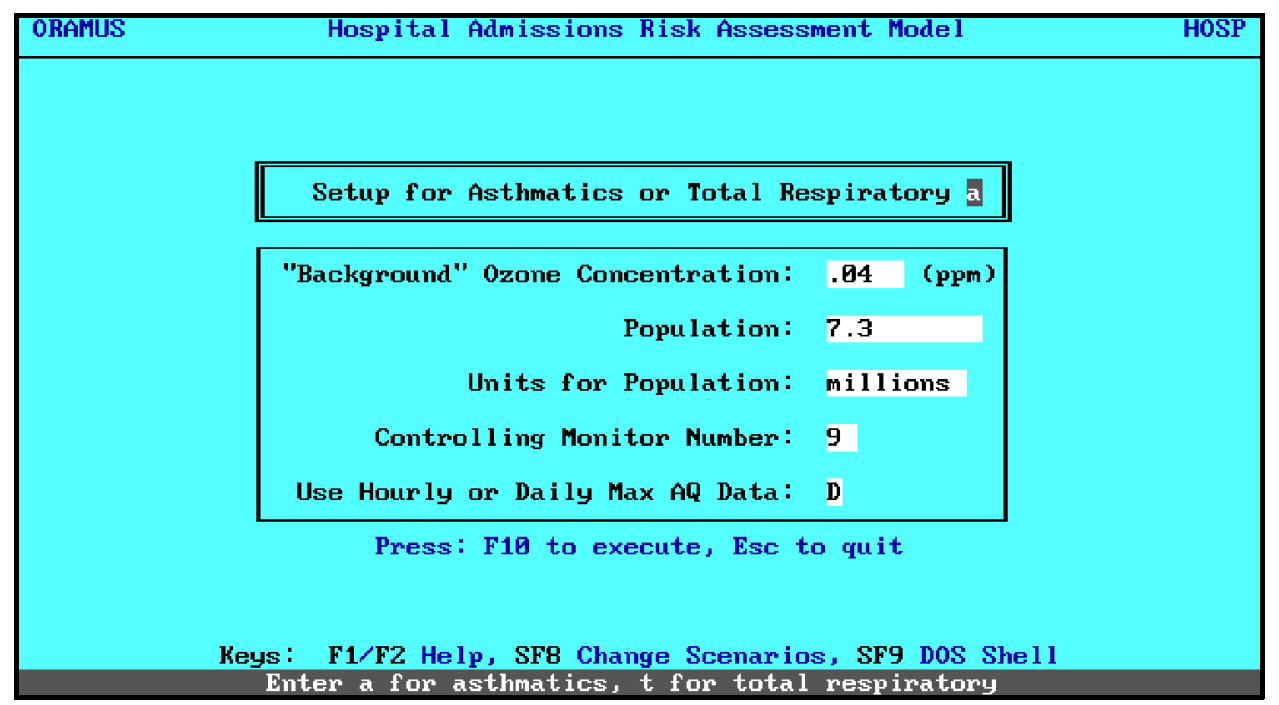

HOSP - Setup Form for Hospital Admissions Model Calculations

In the hospital admissions model, you can choose between admissions of asthmatics or admissions for respiratory ailments. To continue the tutorial, complete the steps on the following page. 
1. Enter a for asthmatics in the first field.

2. Enter $\mathbf{0 . 0 4}$ for the "background" ozone concentration in the second field (for $0.04 \mathrm{ppm}$ ).

3. Enter $\mathbf{7 . 3}$ for the population size in millions (for the New York City area).

4. Enter 9 for the controlling monitor number ( 9 is the monitor used by Thurston et al. [1992]; other allowable choices are monitors 1, 11, and 12).

Two additional fields are "display only" fields (i.e., you cannot modify their contents):

$<$ Units for population (fixed at millions) and

$<$ Type of air quality data (fixed at 1-hour daily maximum values; the form is designed to accommodate hourly values as a future enhancement).

The number and order of scenarios used in the ensuing calculations are controlled by the file named PickAQS.sav.

5. Optional: if you would like to view or change the set of scenarios to be used (there is no indication in Form HOSP as to which scenarios are active), press Shift-F8 (SF8) and proceed as described earlier.

6. When you are satisfied with your choices of scenarios in Form HOSP, press F10 to continue.

ORAMUS pauses three times as data and results are written to the screen. Press any key to end a pause.

$<$ The first pause follows information about the response rate at the background ozone concentration specified in Form HOSP. Risk results are then calculated. While results are being calculated, the name of the output file is displayed on the screen. The file name begins with either ASTH for asthmatics or RESP for total respiratory. 
$<$ A second pause follows a table of data for risk distributions.

$<$ A third pause follows statistics about the results. (Table 4 lists the information you should see while following the tutorial.)

After the third pause, continue with the tutorial.

1. Press any key to display a graph of the risk distributions (shown as cumulative probability distributions).

2. Press any key to display Form P502, which allows you to control characteristics of the graph (ranges and formats for $\mathrm{X}$ - and $\mathrm{Y}$-axis values).

3. Press F5 in Form P502 to create a data file that you can use later to create a vector graphics image file (by using the GEN.EXE utility), as described earlier. The resultant figure should be similar to the graph shown below for excess annual admissions of asthmatics in New York City.

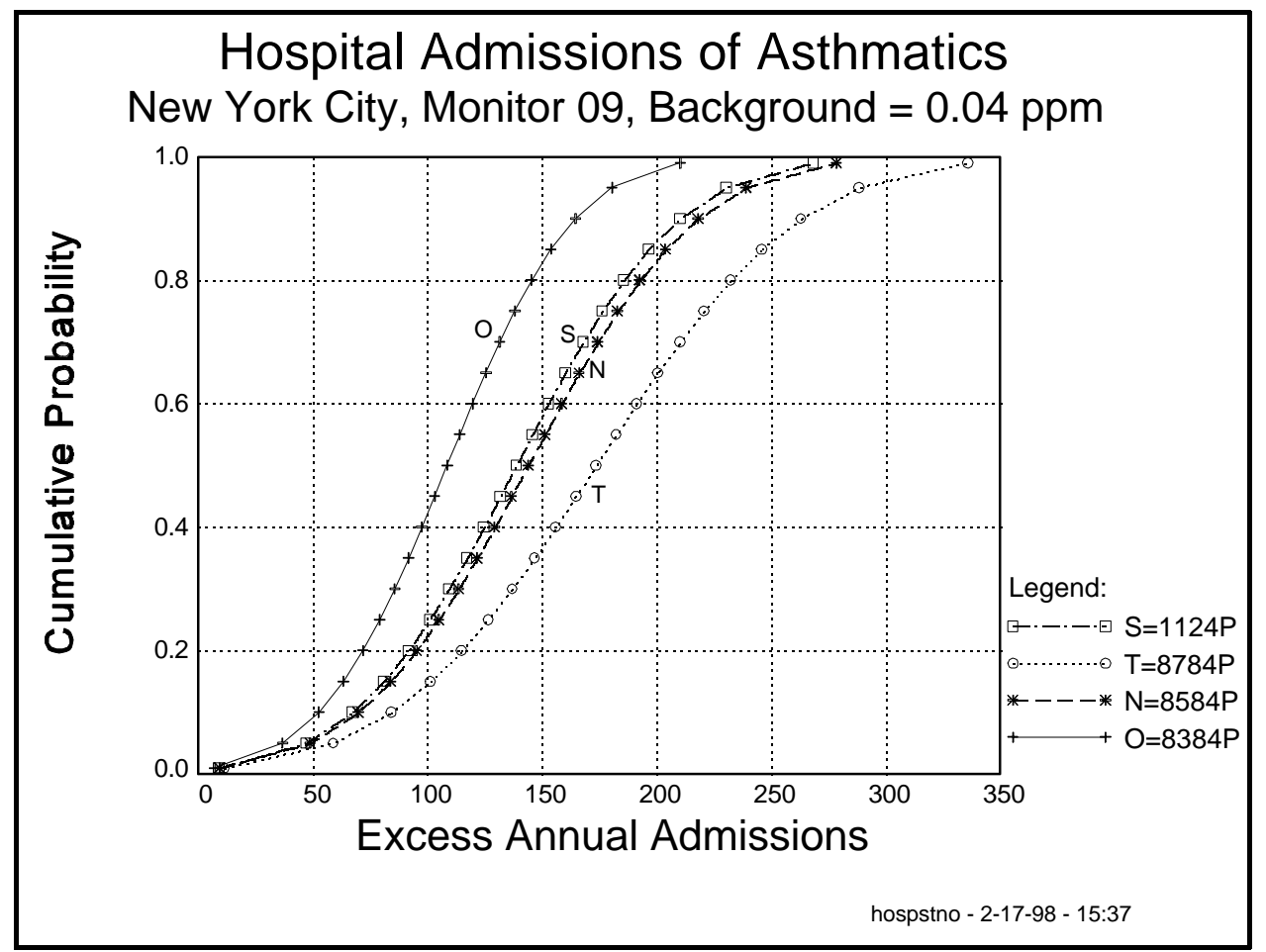

Excess Annual Admissions of Asthmatics in New York City (based on monitor 9 air quality data and a background ozone level of $0.04 \mathrm{ppm}$ ) 
Discussion. The WPG file generated by GEN.EXE was modified in a graphics editor, where the character string "Legend:" and the one-letter scenario codes were added for clarity. The graphics file was then cropped and enlarged in a word processor to achieve the image shown in the figure. 
TABLE 4 Data for Risk Distributions and Statistics Concerning the Results for the Hospital Admissions Model

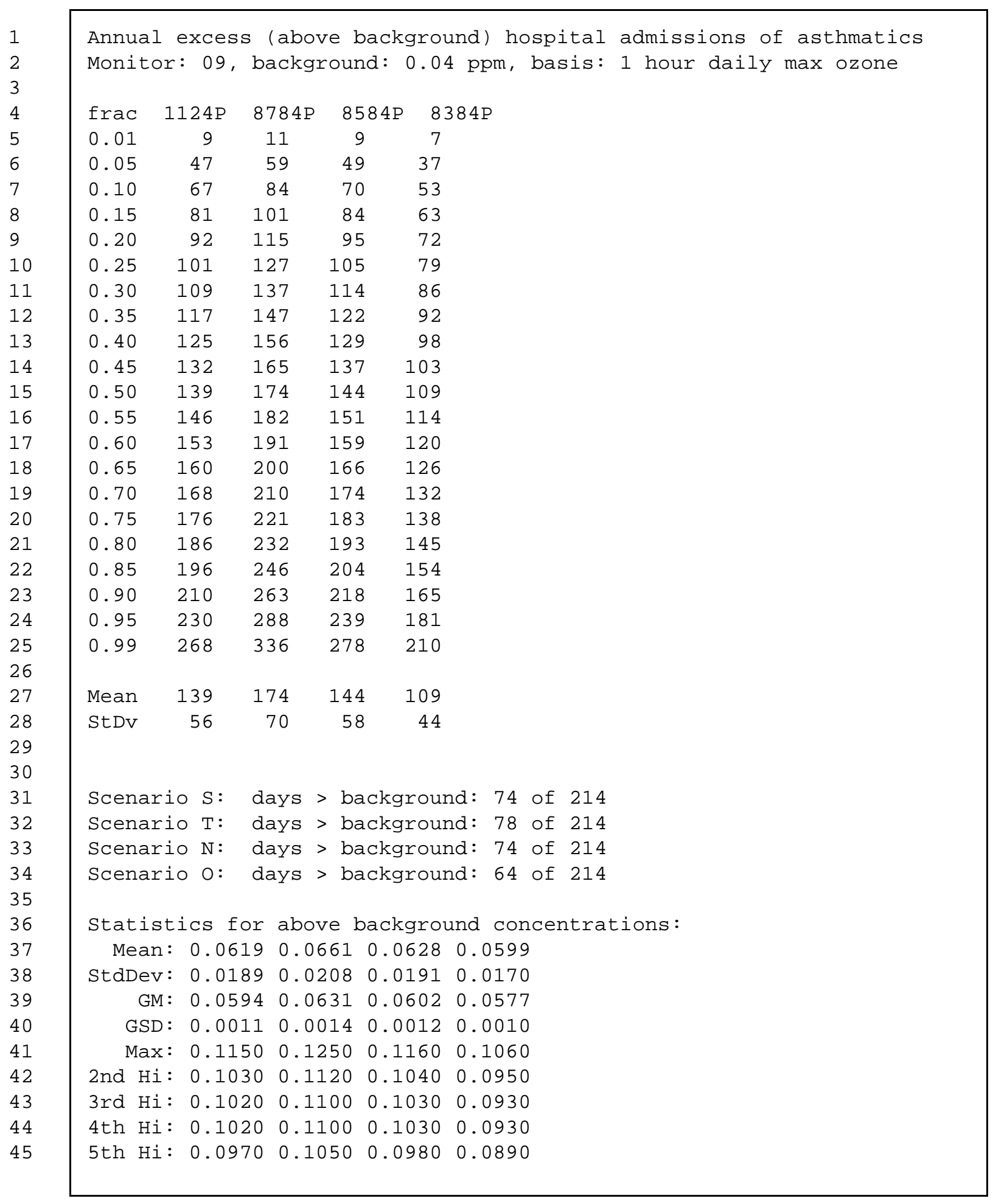




\section{BENCHMARK RISKS}

The second type of risk measure is benchmark risk (Feagans and Biller 1981; Hayes et al. 1987; Whitfield et al. 1994). The first type, headcount risk, focuses on the number of persons affected and the number of incidences of a given health effect in terms of the exposure to individuals as they go about their daily activities.

In contrast, benchmark risk focuses on the probability, or risk, of unhealthful air. Headcount risk measures the risk posed to a population by exposure to ozone. Benchmark risk treats the risk of unhealthful air as a hazard or the presence of a source of danger without regard to the number of people who may or do come in contact with it.

Air quality data and exposure-response probabilities (derived from the same exposure-response relationships used to compute headcount risks for acute health endpoints) are combined to obtain benchmark risk estimates. Unlike headcount risk estimates, for which results of $10 \mathrm{pNEM} / \mathrm{O}_{3}$ runs are available, benchmark risk calculations have only one estimate for air quality data.

Benchmark response $r$ is the fraction of the population that experiences the specified health effect when exposed to ozone. Benchmark risk is the probability that the benchmark response is $\$ r, n$ or more times in a given period (e.g., 1 ozone season) at some location within a geographic region, given a specific condition of air quality (e.g., that Standard 1112 is just attained). ORAMUS uses $r$ values of $0.01,0.05$, and 0.1 (sometimes referred to as $0.01,0.05$, and 0.1 benchmarks or $1 \%, 5 \%$, and $10 \%$ benchmarks) in its calculations.

Benchmark risk results are contained in files that have a .BMR extension. The benchmark risk files were obtained by running a set of Clarion programs (CONVERT, PROBEX, and BRISK) written by William F. Biller, an EPA consultant. These programs, among other things, create the necessary 1-hour daily maximum, the 8-hour daily maximum, and the 8-hour running-average air quality datasets from 1-hour, $\mathrm{pNEM} / \mathrm{O}_{3}$ datasets. 
Because the output files for the benchmark risk model require nearly as much space as the input files, ORAMUS includes only the risk output files. This feature means that graphs of results can be viewed without performing a computation step.

Benchmark risk results are provided for all combinations of the following factors:

$<9$ urban areas;

$<33$ acute health endpoints;

$<9$ air quality scenarios (i.e., 8 alternative air quality standards and 1 scenario representing As-Is air quality);

$<2$ ozone concentration sets (24 concentrations per day, or 1 daily maximum concentration) for each day in the ozone season);

$<3$ values of $r(0.01,0.05$, and 0.1$)$; and

$<2$ levels for the $n$ 'th highest ozone concentration (i.e., first and fifth highest values).

To access the benchmark risk model from Form M000 (the main form), follow these steps:

1. Type b (for benchmark risk) in Form M000.

2. Press F10 to display Form BMBOX2 (see the example on the next page).

3. Mark at least one item in each of the four groups of fields. (See Discussion on the next page.)

4. To process your choices, press F10. 


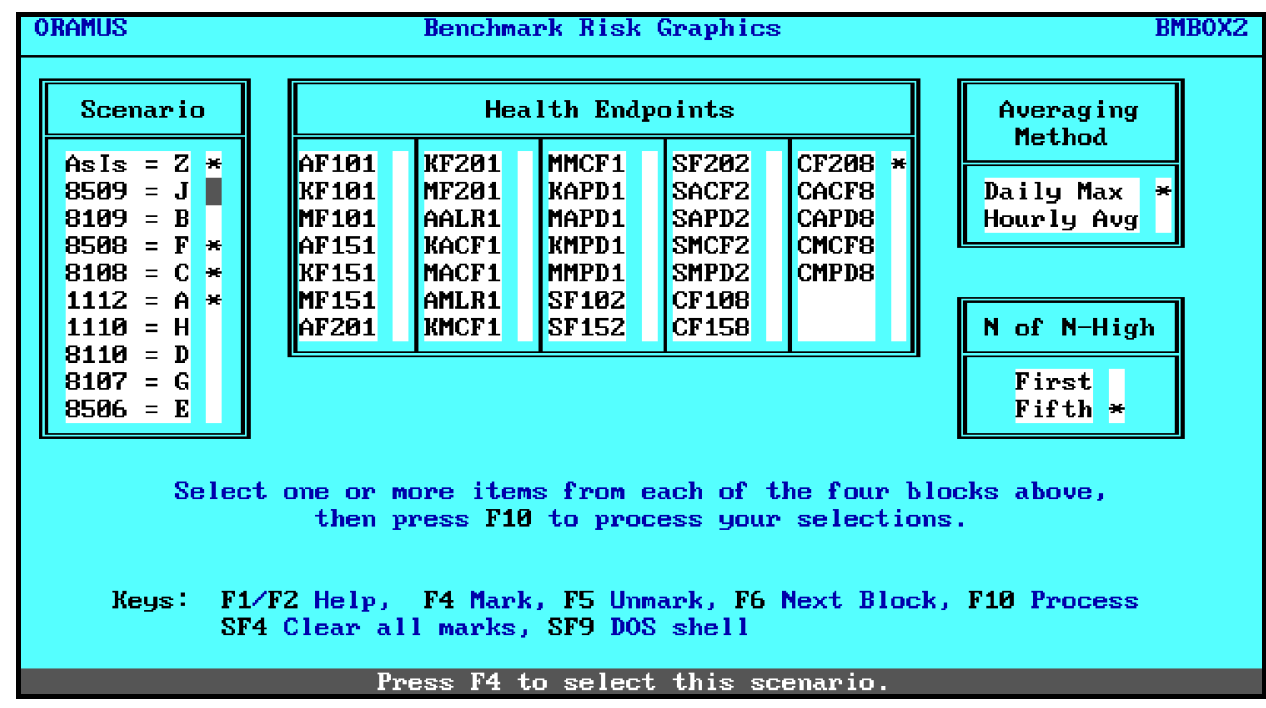

BMBOX2 - Form for Selecting Benchmark Risk Results for Graphing

Discussion. Form BMBOX2 has four groups of fields that allow you to select:

$<$ Air quality scenarios (As-Is plus 8 alternative standards),

$<$ Health endpoints (33 acute health endpoints),

$<$ Averaging time method (i.e., ozone concentration data: 1-hour daily maximum, hourly average), and

$<$ Level for the $n$ 'th highest ozone concentration (allowable choices are the first- and fifth-highest values).

One graph is created for each health endpoint selected. The graph can include results for any or all of the 9 urban areas for which air quality data are available (Chicago, Denver, Houston, Los Angeles, Miami, New York City, Philadelphia, St. Louis, and Washington, D.C.).

To eliminate an urban area from the graphs, simply hide the .BMR files that you want to exclude. For example, to hide the Chicago files,

1. Press Shift-F9 (SF9) to shell to DOS.

2. Enter the following DOS command: attrib ?????c??.bmr +h.

3. Enter exit to return to Form BMBOX2. 
The figure below does not show benchmark risk results for Chicago, Denver, or Miami because results for these urban areas were "hidden" as described in Step 2 on the previous page.

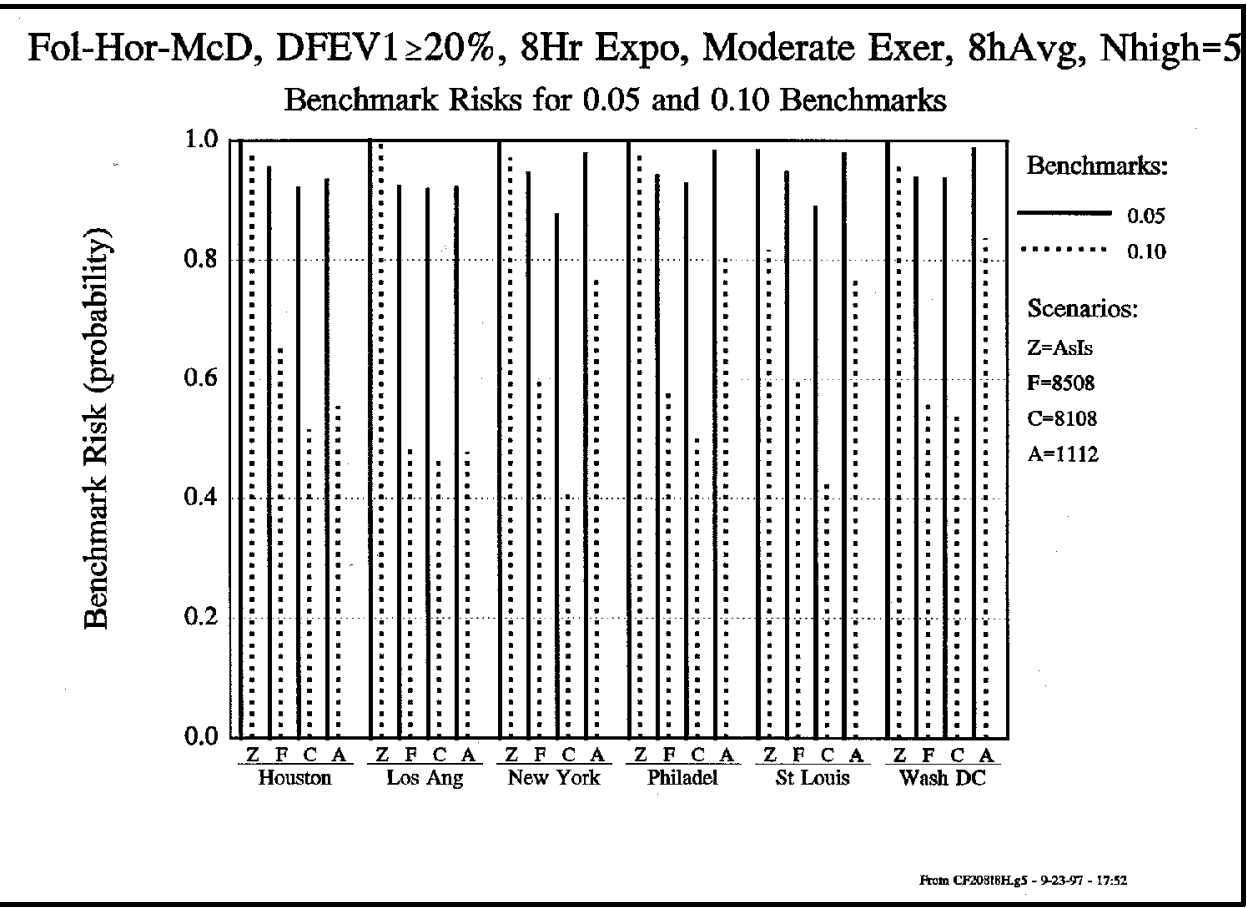

Sample Benchmark Risk Graph

Unhiding Files. To "unhide" the Chicago files for later use, enter the following DOS command:

\section{attrib ?????c??.bmr -h.}

Scenario 8506 (8-hour exposure, 5 expected exceedances, $0.06 \mathrm{ppm}$ of ozone) was one of the first six scenarios studied. Later, it was dropped from consideration and was not included in recent improvements to $\mathrm{pNEM} / \mathrm{O}_{3}$. Thus, this scenario is no longer supported (you cannot mark it) even though it is still listed in the form.

Benchmark risk results are not available for the recently developed air quality standards of the "average $n$ ' th highest daily maximum" form because the air quality data for all urban areas (except New York City) needed to accommodate these new standards have not been developed. 


\section{An Extra Utility — LOOKERF.EXE}

LOOKERF.EXE is an extra utility that allows you to graph selected exposure-response relationships (for 1-hour exposures at heavy exertion, 1-hour exposures at moderate exertion, 8-hour exposures at moderate exertion, and exposures for either 1 or 10 ozone seasons).

1. Change to the ORAMUS directory and enter the DOS command lookerf. (In Windows, double click the LOOKERF icon.)

2. Follow the prompts. At the first prompt, specify 1 for 1 -hour exposures at heavy exertion.

3. When you are asked to provide a filename, you can, for example, enter $\mathbf{m}^{\star}$ to view all exposure-response relationships based on the human exposure studies by McDonnell et al. (1983).

4. When a graph is present on the screen, press $\mathbf{F 8}$ to begin the process of creating a vector graphics image file.

As described on pages 25 and 26, you can control titles, axis labels, and data ranges for the graph. The results are saved in a [filename].GEN file, which is an ASCII file. You can then process the .GEN file by using GEN.EXE to create a WordPerfect graphics ([filename].WPG) file, which can be included in a document.

\section{FIXSAV.BAT}

If an unrecoverable error corrupts key "save" files (namely, A000.sav, C000.sav, or PickAQS.sav), go to DOS, change to the ORAMUS directory, and enter fixsav. FIXSAV.BAT restores earlier versions of these three files (that have the extension SA@), which should be intact. 


\section{GEN.EXE - A Vector Graphics Generator}

The vector graphics generator, GEN.EXE, is included in the complete installation of ORAMUS. You can copy it to a directory specified in your path for uses other than ORAMUS. Note, however, that GEN.EXE must be in the ORAMUS directory for graphing functions in ORAMUS to work properly.

1. To obtain help on GEN.EXE, at the DOS prompt, enter either gen ? or gen $-\mathbf{h}$.

2. Unless otherwise specified, GEN.EXE will try to create WPG and HPGL files on the d: drive. You will get errors if it is not possible to write to the d: drive. To override this restriction, either specify legal file names (on any valid drive in any valid directory) or use NUL. For example, to generate a screen version of the file defined in GEN.DAT without producing a WPG or an HPGL file, enter gen gen.dat nul nul.

The default names of the WPG and HPGL files are d: GEN.WPG and d: GEN.HPG, respectively.

3. To produce a WPG file, but not an HPGL file, enter gen gen.dat gen.wpg nul.

Be careful not to use GEN.DAT as the name for the WPG file or the HPGL file. If you do, you will lose the input data file.

To install the sample files relating to GEN.EXE, create and change to a directory of your choosing (to avoid confusion, it is recommended that you not install the sample output files in the ORAMUS directory structure) and perform the following steps:

1. Place disk ORADOS3 in drive a:.

\section{Enter a:genplot.}

The self-extracting ZIP file GENPLOT.EXE contains sample input and output files and a user's manual. 


\section{Installation and Use of the ORAMUS Source Code}

If you ordered the Windows installation disks, you have an option to install the source code during the installation process. If you ordered the DOS installation disks, follow the instructions below to install the source code for ORAMUS.

1. Return to the ORAMUS directory.

2. Place disk ORADOS3 in drive a:.

3. Enter a:oracode1 $-\mathbf{d}^{*} . *$.

4. Enter cdl.

5. Enter a:oracode2 $-d^{*} .^{*}$.

The source code and other related files will be copied to their respective directories. The contents of ORACODE1.EXE and ORACODE2.EXE are listed in ORACODE.DIR.

The source code looks for 'INCLUDE' files in a c:BBASEDATA directory. (This is not a strict requirement; however, you have to make extensive changes to the source code if you want to move files from the c:IBASEDATA directory.)

The FORMS package provides functions and subroutines for moving data in and out of forms. Source codes for the suite of FORMS package programs included in the installation disks are FORM.BAS, PAGER.BAS, FORARR.BAS, ATON.BAS, and FMENU.BAS. In addition, two library files are provided that contain all of the FORMPACK functions and subroutines. One library file is for use in the QuickBASIC environment; the other is for use in compiling programs in DOS.

To work with one of the ORAMUS source files that must be linked to FORMPACK, enter the following DOS command:

\section{QBX hcmain /l [drive:]lformslformpack.}

This command loads HCMAIN.BAS (and the files listed in HCMAIN.MAK) and links to FORMPACK.QLB. It is convenient to 
compile ORAMUS programs in the QuickBASIC environment. If you wish to work outside the QuickBASIC environment, pay attention to the messages displayed in the QuickBASIC environment as it compiles and links programs.

\section{Sample Output Files}

Sample output files are included on disk ORADOS3 in SAMPLOUT.EXE, a self-extracting ZIP file. To retrieve these files to the current directory (to avoid confusion, it should not be a directory used by ORAMUS), at the DOS prompt, enter

\section{a:samplout.}

If you ordered the Windows installation disks, the sample output files will be copied to a directory named IORASAMPL on drive c: if you chose to install them.

\section{Running ORAMUS Executables Directly in DOS}

The box plot module can be run directly in DOS (without the "aid" of ORAMUS). In the ORAMUS directory, enter

\section{gohcbox.}

In addition, the benchmark risk model and the hospital admissions model can be run separately. To learn about these and other subtleties, occasionally check the contents of the NEXT.BAT, GENEXT.BAT, and BENCHMRKIGENEXT.BAT files. 


\section{REFERENCES}

Feagans, T.B., and W.F. Biller, 1981, "Describing the Protection Provided by Ambient Air Quality Standards," Environmental Professional 3:235-247.

Hayes, S.R., et al., 1987, Assessment of Lung Function and Symptom Health Risks Associated with Attainment of Alternative Ozone NAAQS, Draft Final Report, SYSAPP-87-171, Systems Applications, Inc., San Rafael, Calif. (For copies, contact H.M. Richmond, U.S. Environmental Protection Agency, Office of Air Quality Planning and Standards, MD-15, Research Triangle Park, N.C.; phone 919-541-5271.)

Johnson, T., 1997, Sensitivity of Exposure Estimates to Air Quality Adjustment Procedure, letter report prepared by TRJ Environmental, Inc., Chapel Hill, N.C., and IT Air Quality Services, Inc., Cary, N.C., for the U.S. Environmental Protection Agency, Office of Air Quality Planning and Standards, Research Triangle Park, N.C., June 20.

Johnson, T., et al., 1996a, Estimation of Ozone Exposures Experienced by Urban Residents Using a Probabilistic Version of NEM and 1990

Population Data, prepared by IT Air Quality Services, Inc., Cary, N.C., for the U.S. Environmental Protection Agency, Office of Air Quality Planning and Standards, Research Triangle Park, N.C., Apr.

Johnson, T., et al., 1996b, Estimation of Ozone Exposures Experienced by Outdoor Workers in Nine Urban Areas Using a Probabilistic Version of NEM, prepared by IT Air Quality Services, Inc., Cary, N.C., for the U.S. Environmental Protection Agency, Office of Air Quality Planning and Standards, Research Triangle Park, N.C., Apr.

Johnson, T., et al., 1996c, Estimation of Ozone Exposures Experienced by Outdoor Children in Nine Urban Areas Using a Probabilistic Version of NEM, prepared by IT Air Quality Services, Inc., Cary, N.C., for the U.S. Environmental Protection Agency, Office of Air Quality Planning and Standards, Research Triangle Park, N.C., Apr. 
Johnson, T., et al., 1997, Supplement to Estimation of Ozone Exposures Experienced by Outdoor Children in Nine Urban Areas Using a Probabilistic Version of NEM, prepared by TRJ Environmental, Inc., Chapel Hill, N.C., and IT Air Quality Services, Inc., Cary, N.C., for the U.S. Environmental Protection Agency, Office of Air Quality Planning and Standards, Research Triangle Park, N.C., Jan.

Johnson, T.R., et al., 1990, "Estimation of Ozone Exposure in Houston Using a Probabilistic Version of NEM," Paper No. 90-150.1, presented at the 83rd Annual Meeting of the Air and Waste Management Association, Pittsburgh, Pa., June.

Jusko, M.J., and R.G. Whitfield, 1996, GENWPG: A WPG Graphics File Generator, Argonne National Laboratory, Argonne, Ill., Sept. 9.

McCurdy, T., 1994, "Human Exposure to Ambient Ozone," in Tropospheric Ozone: Human Health and Agricultural Impacts, D.J. McKee, editor, Lewis Publishers, Inc., Boca Raton, Fla.

McCurdy, T., et al., 1991, "Preliminary Analyses of Ozone Exposures in Houston Using $\mathrm{pNEM} / \mathrm{O}_{3}$," paper presented at the 84th Annual Meeting of the Air and Waste Management Association, Vancouver, B.C., Canada, June.

McDonnell, W.F., et al., 1983, "Pulmonary Effects of Ozone Exposure during Exercise: Dose-Response Characteristics," Journal of Applied Physiology: Respiratory Environmental Exercise Physiology 54:1345-1352.

Paul, R.A., et al., 1986, National Estimates of Exposure to Ozone under Alternative National Standards, prepared for the U.S. Environmental Protection Agency, Research Triangle Park, N.C.

Thurston, G.D., et al., 1992, “A Multi-Year Study of Air Pollution and Respiratory Hospital Admissions in Three New York State Metropolitan Areas: Results for 1988 and 1989 Summers," Journal of Exposure Analysis and Environmental Epidemiology 2:429-450.

Whitfield, R.G., et al., 1994, "Health Risk Assessment of Ozone," in Tropospheric Ozone: Human Health and Agricultural Impacts, D.J. McKee, editor, Lewis Publishers, Inc., Boca Raton, Fla. 
Whitfield, R.G., et al., 1996, A Probabilistic Assessment of Health Risks Associated with Short-Term Exposure to Tropospheric Ozone, ANL/DIS-3, Argonne National Laboratory, Argonne, Ill., June.

Whitfield, R.G., 1997a, A Probabilistic Assessment of Health Risks Associated with Short-Term Exposure to Tropospheric Ozone: A Supplement, letter report from Argonne National Laboratory, Argonne, Ill., to the U.S. Environmental Protection Agency, Office of Air Quality Planning and Standards, Research Triangle Park, N.C., Jan.

Whitfield, R.G., 1997b, Sensitivity of Health Risk Estimates to Air Quality Adjustment Procedure, letter report from Argonne National Laboratory, Argonne, Ill., to the U.S. Environmental Protection Agency, Office of Air Quality Planning and Standards, Research Triangle Park, N.C., June 30. 


\section{APPENDIX A:}

FORMATS OF PRINCIPAL INPUT AND OUTPUT FILES

This appendix explains the formats of the principal input and output files for each one of the three ORAMUS models.

\section{A.1 HEADCOUNT RISK FILES}

The principal input files for both acute and chronic endpoints are exposure probability and exposure-response files. Each urban area, population, exposure time, and air quality scenario has one exposure file, and each health endpoint has one exposure-response file. The principal output files are headcount risk results files.

\section{A.1.1 Headcount Risk Exposure Probability File Format}

Table A.1 lists the exposure file for Philadelphia, children, 8-hour exposures, and Scenario 1112. Lines 1 and 5 are headers. Line 5 indicates that there are data for $10 \mathrm{pNEM} / \mathrm{O}_{3}$ runs. Lines 6-20 are exposure probabilities. Each line has one probability for each run that specifies the fraction (of children) who are exposed at the ozone concentration (actually, the interval for which the listed concentration is the midpoint) listed at the beginning of the line. For 8-hour exposures, there are 15 exposure concentrations (parts per million [ppm] of ozone). For 1-hour exposures (at both heavy and moderate exertion), there are 18 exposure concentrations. For chronic endpoints, there are 9 exposure concentrations. Two blank lines follow the exposure probabilities and separate two lines for total head count (TotalHC) and corrected head count (HC-Corr). In Table A.1, TotalHC is the number of children who reached moderate levels of exertion; HC-Corr is the subset of children who were exposed at ozone levels above background (0.04 ppm). The numbers differ from run to run. 
TABLE A.1 Exposure Probability File for Headcount Risk Endpoints: Philadelphia, Children, 8-hour Exposures, Scenario 1112

\begin{tabular}{|c|c|c|c|c|c|c|c|c|c|c|c|}
\hline $\begin{array}{c}\text { Line } \\
\text { Number }\end{array}$ & \multicolumn{10}{|c|}{ Contents of Line } & \\
\hline 1 & \multirow[t]{4}{*}{ City $=\mathrm{PH}$, } & \multicolumn{4}{|c|}{ Population $=\mathrm{C}$, Hours Exposed $/$ Exceedance $=1 \mathrm{H} 12$, } & \multicolumn{2}{|c|}{ Measurement $=\mathrm{P}$} & & & & \\
\hline 2 & & & & & & & & & & & \\
\hline 3 & & & & & & & & & & & \\
\hline 4 & & & & & & & & & & & \\
\hline 5 & PPM & Run 1 & Run 2 & Run 3 & Run 4 & Run 5 & Run 6 & Run 7 & Run 8 & Run 9 & Run 10 \\
\hline 6 & 0.051 & 0.157553 & 0.141316 & 0.173341 & 0.129553 & 0.151198 & 0.181955 & 0.128321 & 0.139692 & 0.159285 & 0.152066 \\
\hline 7 & 0.066 & 0.224616 & 0.174551 & 0.141949 & 0.204137 & 0.217086 & 0.246667 & 0.260423 & 0.208873 & 0.226939 & 0.211554 \\
\hline 8 & 0.076 & 0.314832 & 0.379686 & 0.430594 & 0.396212 & 0.369539 & 0.293863 & 0.337486 & 0.372635 & 0.351341 & 0.337323 \\
\hline 9 & 0.086 & 0.183113 & 0.186846 & 0.173721 & 0.184778 & 0.145080 & 0.199141 & 0.160145 & 0.166062 & 0.198523 & 0.180043 \\
\hline 10 & 0.096 & 0.067686 & 0.042216 & 0.028784 & 0.020888 & 0.046979 & 0.020710 & 0.043267 & 0.042970 & 0.022654 & 0.041188 \\
\hline 11 & 0.106 & 0.000000 & 0.004766 & 0.000000 & 0.002885 & 0.000000 & 0.009947 & 0.000000 & 0.001444 & 0.002172 & 0.002154 \\
\hline 12 & 0.116 & 0.000000 & 0.000000 & 0.000000 & 0.000000 & 0.000000 & 0.000000 & 0.000000 & 0.000000 & 0.000000 & 0.000000 \\
\hline 13 & 0.126 & 0.000000 & 0.000000 & 0.000000 & 0.000000 & 0.000000 & 0.000000 & 0.000000 & 0.000000 & 0.000000 & 0.000000 \\
\hline 14 & 0.136 & 0.000000 & 0.000000 & 0.000000 & 0.000000 & 0.000000 & 0.000000 & 0.000000 & 0.000000 & 0.000000 & 0.000000 \\
\hline 15 & 0.146 & 0.000000 & 0.000000 & 0.000000 & 0.000000 & 0.000000 & 0.000000 & 0.000000 & 0.000000 & 0.000000 & 0.000000 \\
\hline 16 & 0.156 & 0.000000 & 0.000000 & 0.000000 & 0.000000 & 0.000000 & 0.000000 & 0.000000 & 0.000000 & 0.000000 & 0.000000 \\
\hline 17 & 0.166 & 0.000000 & 0.000000 & 0.000000 & 0.000000 & 0.000000 & 0.000000 & 0.000000 & 0.000000 & 0.000000 & 0.000000 \\
\hline 18 & 0.176 & 0.000000 & 0.000000 & 0.000000 & 0.000000 & 0.000000 & 0.000000 & 0.000000 & 0.000000 & 0.000000 & 0.000000 \\
\hline 19 & 0.186 & 0.000000 & 0.000000 & 0.000000 & 0.000000 & 0.000000 & 0.000000 & 0.000000 & 0.000000 & 0.000000 & 0.000000 \\
\hline 20 & 0.196 & 0.000000 & 0.000000 & 0.000000 & 0.000000 & 0.000000 & 0.000000 & 0.000000 & 0.000000 & 0.000000 & 0.000000 \\
\hline \multicolumn{12}{|l|}{21} \\
\hline \multicolumn{12}{|l|}{22} \\
\hline 23 & TotalHC & 266628 & 268569 & 268413 & 269010 & 267590 & 270738 & 268912 & 270796 & 263798 & 266003 \\
\hline 24 & HC-Corr & 252710 & 249603 & 254560 & 252453 & 248827 & 257819 & 249992 & 252294 & 253487 & 245874 \\
\hline
\end{tabular}




\section{A.1.2 Headcount Risk Exposure-Response File Format}

Table A.2 is an example of an exposure-response file $\left(\mathrm{FEV}_{1} \$ 20 \%, 8\right.$-hour exposures at moderate exertion). Only a portion of the file can be shown ( 8 of the 16 numbers that are in each line). The first three lines give header information. The next 21 lines specify the fractional response rate for specific exposure concentrations and fractiles. For example, the median response $[R(11)]$ is listed in line 14 , the 0.01 -fractile response $[R(1)]$ is listed in line 4, and the 0.99-fractile response [R(21)] is listed in line 24 . The first numerical entry is the response rate at background [in this case, it is 0 , as are all entries under "COL(1)"]. To coincide with the exposure probability files, there are 15 probabilities in each line (not all can be shown here) that correspond to the ppm values listed in Table A.1 for 8-hour exposures at moderate exertion. In contrast, there are 18 entries for 1-hour endpoints (heavy and moderate exertion) and 10 entries for chronic health endpoints.

\section{A.1.3 Headcount Risk Results File Format}

While the exposure probability and exposure-response files vary in size, depending on health endpoint, the format for risk results files is the same for all health endpoints and exposure durations. The output file (see Table A.3) consists of three sections. The top section (lines 1-12) contains information about the exposure and exposure-response files used to calculate results. The middle section (lines 13-37) lists the fractional response rates with no correction for background. The bottom section (lines 41-65) lists the number of children responding after correction for background ozone. Because of space limitations, the table contains results only for runs 1-6. Below the data for the probability distribution for each run are the mean, standard deviation, and number of people (children) associated with the $\mathrm{pNEM} / \mathrm{O}_{3}$ run (lines 35-37 for uncorrected results, lines 63-65 for corrected results). Because there is no response at the $0.04 \mathrm{ppm}$ background ozone level, uncorrected and corrected results are identical (e.g., for run 1, the total headcount is 266,628 [in line 65] and the 0.99 -fractile fractional response rate is 0.149968 [in line 33]; the product of these two numbers is 39,986 , which is the result listed in line 61). 
TABLE A.2 Portion of an Exposure-Response Relationship File for Headcount Risks: FEV $\mathbf{1} \mathbf{2 0 \%}$, 8-hour Exposures at Moderate Exertion

\begin{tabular}{|c|c|c|c|c|c|c|c|c|c|}
\hline $\begin{array}{c}\text { Line } \\
\text { Number }\end{array}$ & \multicolumn{9}{|c|}{ Contents of Line } \\
\hline 1 & $\begin{array}{lll}1 & 30 & 0\end{array}$ & 217 & & & & & & & \\
\hline 2 & 022222222 & 22222 & & & & & & & \\
\hline 3 & "LABEL\$" & "COL(1)" & "COL(2)" & "COL(3)" & "COL(4)" & "COL(5)" & "COL(6)" & "COL(7)" & "COL(8)" \\
\hline 4 & "R(1)" & 0.0000000000 & 0.0000000000 & 0.0063806608 & 0.0186047372 & 0.0304082267 & 0.0371871195 & 0.0465733983 & 0.0618410958 \\
\hline 5 & "R(2)" & 0.0000000000 & 0.0000000000 & 0.0123324120 & 0.0293271892 & 0.0453648564 & 0.0565038711 & 0.0702623090 & 0.0897074299 \\
\hline 6 & "R(3)" & 0.0000000000 & 0.0000000301 & 0.0168255211 & 0.0365479400 & 0.0551177016 & 0.0691907923 & 0.0857189892 & 0.1074635363 \\
\hline 7 & "R(4)" & 0.0000000000 & 0.0000002867 & 0.0204543916 & 0.0420576909 & 0.0624358043 & 0.0787368257 & 0.0973017501 & 0.1206042519 \\
\hline 8 & "R(5)" & 0.0000000000 & 0.0000014177 & 0.0237067937 & 0.0468170048 & 0.0686862700 & 0.0869012714 & 0.1071777149 & 0.1317141629 \\
\hline 9 & "R(6)" & 0.0000000000 & 0.0000048983 & 0.0267689886 & 0.0511747124 & 0.0743592378 & 0.0943167728 & 0.1161242869 & 0.1417120538 \\
\hline 10 & "R(7)" & 0.0000000000 & 0.0000134935 & 0.0297401417 & 0.0553077255 & 0.0797002328 & 0.1013008084 & 0.1245304307 & 0.1510537443 \\
\hline 11 & "R(8)" & 0.0000000000 & 0.0000318014 & 0.0326851050 & 0.0593253534 & 0.0848587238 & 0.1080468572 & 0.1326321897 & 0.1600130802 \\
\hline 12 & "R(9)" & 0.0000000000 & 0.0000668933 & 0.0356537600 & 0.0633062357 & 0.0899402695 & 0.1146916151 & 0.1405953497 & 0.1687799750 \\
\hline 13 & "R(10)" & 0.0000000000 & 0.0001290943 & 0.0386902491 & 0.0673150937 & 0.0950298752 & 0.1213451330 & 0.1485523776 & 0.1775038595 \\
\hline 14 & "R(11)" & 0.0000000000 & 0.0002329998 & 0.0418386941 & 0.0714122368 & 0.1002049504 & 0.1281075402 & 0.1566227681 & 0.1863172616 \\
\hline 15 & "R(12)" & 0.0000000000 & 0.0003989160 & 0.0451479731 & 0.0756605746 & 0.1055445221 & 0.1350809204 & 0.1649273086 & 0.1953519327 \\
\hline 16 & "R(13)" & 0.0000000000 & 0.0006550867 & 0.0486770823 & 0.0801325845 & 0.1111380287 & 0.1423806123 & 0.1736014311 & 0.2047534499 \\
\hline 17 & "R(14)" & 0.0000000000 & 0.0010414263 & 0.0525027108 & 0.0849193709 & 0.1170963369 & 0.1501493624 & 0.1828117074 & 0.2146988346 \\
\hline 18 & "R(15)" & 0.0000000000 & 0.0016162688 & 0.0567316555 & 0.0901449267 & 0.1235688755 & 0.1585792187 & 0.1927811482 & 0.2254230727 \\
\hline 19 & "R(16)" & 0.0000000000 & 0.0024696060 & 0.0615238412 & 0.0959920801 & 0.1307744202 & 0.1679508646 & 0.2038344545 & 0.2372662455 \\
\hline 20 & "R(17)" & 0.0000000000 & 0.0037518676 & 0.0671404430 & 0.1027561486 & 0.1390645519 & 0.1787145326 & 0.2164908255 & 0.2507697609 \\
\hline 21 & "R(18)" & 0.0000000000 & 0.0057460956 & 0.0740607300 & 0.1109746449 & 0.1490765024 & 0.1916845471 & 0.2316866018 & 0.2669066650 \\
\hline 22 & "R(19)" & 0.0000000000 & 0.0090955503 & 0.08333383556 & 0.1218206540 & 0.1621954759 & 0.2086264100 & 0.2514454578 & 0.2877733539 \\
\hline 23 & "R(20)" & 0.0000000000 & 0.0158996932 & 0.0982490267 & 0.1389108587 & 0.1826714070 & 0.2349356874 & 0.2819257151 & 0.3197256241 \\
\hline 24 & "R(21)" & 0.0000000000 & 0.0347223261 & 0.1298555992 & 0.1740908054 & 0.2241670207 & 0.2876873175 & 0.3422845453 & 0.3822398438 \\
\hline
\end{tabular}


TABLE A.3 Risk Results File for Headcount Risks: FEV $\mathbf{\$ 2 0 \%}$, Philadelphia, Outdoor Children, Scenario 1112

Line

Number

Contents of Line

1

$2 \quad 07-26-1995 \quad 07: 32: 45$

3

4 CF208.ERF

5 Health File: Study: C, Symptom: F20, Hours Exp: 8

6

$7 \quad$ PHC1112.8P

8 Exposure File: City $=$ PH, Population $=$ C, Hours Exposed $/$ Exceedance $=1 \mathrm{H} 12$,

Measurement $=\mathrm{P}$

9

10

11

FRAC RUN 1

\section{RUN 2}

RUN 3

RUN 4

RUN 5

RUN 6

0.01

0.015376

0.015651

0.015270

0.015204

0.014419

0.014330

15

16

0.05

0.024135

0.024484

0.023886

0.023903

0.022751

0.022563

$6 \quad 0.15$

0.030062

0.030442

0.029692

0.029793

0.028405

0.028152

17

0.034598

0.034993

0.034126

0.034301

0.032740

0.032437

$18 \quad 0.25$

0.038524

0.038927

0.037958

0.038205

0.036495

0.036150

$19 \quad 0.30$

0.042125

0.042532

0.041469

0.041786

0.039942

0.039559

$20 \quad 0.35$

$0.045546 \quad 0.045954$

0.044801

0.045188

0.043218

0.042799

$21 \quad 0.40$

0.048876

0.049284

0.048042

0.048501

0.046411

0.045957

$\begin{array}{ll}0.052182 & 0.052586\end{array}$

0.051258

0.051790

0.049581

0.049095

$22 \quad 0.45$

0.055518

0.055917

0.054501

0.055109

0.052782

0.052264

$23 \quad 0.50$

0.058937

0.057824

0.058509

0.056064

0.055514

$24 \quad 0.55$

0.062494

0.062873

0.061280

0.062045

0.059479

0.058899

$25 \quad 0.60$

0.066253

0.064933

0.065782

0.063091

0.062482

$26 \quad 0.65$

0.070297

0.070643

0.068863

0.069799

0.066978

0.066342

$27 \quad 0.70$

0.074739

0.075059

0.073180

0.074208

0.071249

0.070588

$28 \quad 0.75$

$\begin{array}{ll}0.079744 & 0.080031\end{array}$

0.078048

0.079173

0.076065

0.075382

$29 \quad 0.80$

0.085584

0.085825

0.083730

0.084959

0.081686

0.080988

$30 \quad 0.85$

0.092751

0.090709

0.092051

0.088589

0.087887

$31 \quad 0.90$

0.102326

0.102397

0.100044

0.101511

0.097817

0.097132

$\begin{array}{ll}32 & 0.95\end{array}$

0.117658

0.117532

0.115013

0.116629

0.112604

0.111996

$33 \quad 0.99$

0.149968

0.149334

0.146637

0.148401

0.143811

0.143511 
TABLE A.3 (Cont.)

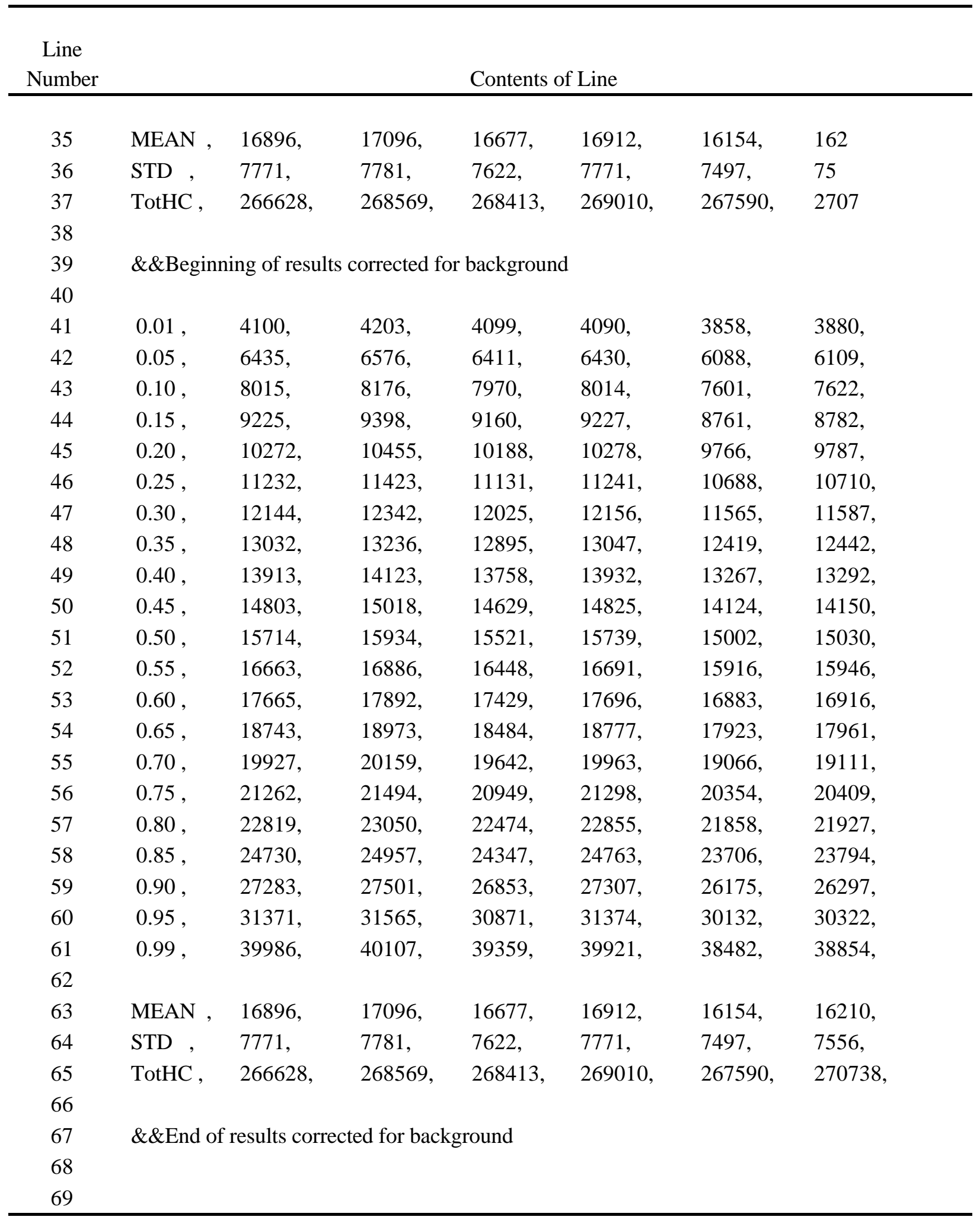




\section{A.2 HOSPITAL ADMISSIONS FILES}

\section{A.2.1 Air Quality Data File Format}

ORAMUS includes data for four New York City monitors (1, 9, 11, and 12), one data file for each of the 27 air quality scenarios. Each file contains 1-hour daily maximum ozone levels (in ppm) for the New York City ozone season (214 days). The format for each file is the same; Table A.4 lists the file (NY09S1D.AQD) for monitor 9, Scenario S (1124P). Each line in the file begins with a monitor identification number followed by twelve 1-hour daily maximum ozone concentrations.

\section{A.2.2 Concentration-Response Relationship Format}

There are two concentration-response relationship files, one for asthmatics (ASTHADM.CRF) and the other for total respiratory admissions (RESPADM.CRF). Each of these files is similar to the exposure-response relationship file shown in Table A.2. Each also has 24 lines, 18 of which define the concentration-response relationship; each line, however, contains 41 data entries (for 0-0.4 ppm in steps of $0.01 \mathrm{ppm}$ ).

\section{A.2.3 Output File Format}

There is an output file for each choice of admissions type, monitor, and background ozone level. The file specification incorporates these choices (e.g., ASTH091D.04, in which the characters 1D denote use of 1-hour daily maximum ozone concentrations). An example file is shown in Table 4 in the main text. The first four lines contain header information, which includes identification of the air quality scenarios used in the calculations. The probability distributions are listed in lines 5-25; the means and standard deviations are listed in lines 27 and 28, respectively; a listing of the number of days having 1-hour daily maximum ozone levels in excess of the specified background level begins in line 31 (there is one line for each scenario); and the last nine lines contain statistics about the ozone levels that are above background. Each line has an entry for each air quality scenario. A maximum of 10 air quality scenarios can be listed. 
TABLE A.4 Air Quality Data File for the Hospital Admissions Model

\begin{tabular}{|c|c|c|c|c|c|c|c|c|c|c|c|c|c|}
\hline $\begin{array}{c}\text { Line } \\
\text { Number }\end{array}$ & \multicolumn{13}{|c|}{ Contents of Line } \\
\hline 1 & $360810004 X X X X X$ & .011 & .016 & .017 & .010 & .023 & .019 & .025 & .027 & .033 & .033 & .029 & .026 \\
\hline 2 & $360810004 X X X X X$ & .026 & .034 & .031 & .036 & .028 & .026 & .034 & .033 & .020 & .037 & .026 & .031 \\
\hline 3 & $360810004 X X X X X$ & .026 & .026 & .035 & .053 & .030 & .012 & .043 & .031 & .039 & .036 & .028 & .037 \\
\hline 4 & $360810004 \mathrm{XXXXX}$ & .036 & .040 & .045 & .025 & .027 & .033 & .029 & .039 & .037 & .027 & .016 & .026 \\
\hline 5 & $360810004 X X X X X$ & .029 & .023 & .015 & .023 & .025 & .030 & .036 & .036 & .049 & .043 & .027 & .028 \\
\hline 6 & $360810004 X X X X X$ & .026 & .053 & .062 & .032 & .036 & .036 & .045 & .044 & .030 & .044 & .036 & .017 \\
\hline 7 & $360810004 X X X X X$ & .032 & .056 & .026 & .029 & .050 & .026 & .031 & .043 & .035 & .047 & .068 & .057 \\
\hline 8 & $360810004 X X X X X$ & .038 & .019 & .047 & .030 & .065 & .084 & .044 & .053 & .027 & .059 & .089 & .061 \\
\hline 9 & $360810004 X X X X X$ & .043 & .052 & .043 & .080 & .042 & .013 & .012 & .020 & .028 & .019 & .060 & .088 \\
\hline 10 & $360810004 X X X X X$ & .103 & .077 & .094 & .074 & .050 & .049 & .028 & .047 & .054 & .027 & .023 & .044 \\
\hline 11 & $360810004 X X X X X$ & .044 & .079 & .034 & .041 & .078 & .095 & .082 & .036 & .041 & .061 & .036 & .012 \\
\hline 12 & $360810004 X X X X X$ & .081 & .115 & .073 & .053 & .062 & .090 & .091 & .097 & .036 & .017 & .014 & .022 \\
\hline 13 & $360810004 X X X X X$ & .010 & .009 & .031 & .078 & .066 & .063 & .042 & .046 & .057 & .102 & .102 & .027 \\
\hline 14 & $360810004 X X X X X$ & .031 & .036 & .076 & .043 & .030 & .023 & .028 & .055 & .057 & .036 & .027 & .028 \\
\hline 15 & $360810004 X X X X X$ & .016 & .016 & .020 & .026 & .026 & .022 & .025 & .022 & .011 & .034 & .044 & .033 \\
\hline 16 & $360810004 X X X X X$ & .071 & .050 & .028 & .014 & .022 & .033 & .036 & .026 & .050 & .048 & .021 & .021 \\
\hline 17 & $360810004 X X X X X$ & .019 & .017 & .015 & .012 & .023 & .029 & .023 & .047 & .030 & .017 & .017 & .034 \\
\hline 18 & $360810004 X X X X X$ & .016 & .019 & .011 & .013 & .012 & .019 & .018 & .016 & .009 & .015 & $*$ & $*$ \\
\hline
\end{tabular}




\section{A.3 BENCHMARK RISK FILES}

The ORAMUS installation includes only output files for benchmark risks. There is one file for each urban area and health endpoint. Each file contains results for all allowable (i.e., nine) air quality scenarios. Table A.5 is the output file for Philadelphia, $\mathrm{FEV}_{1}$ decrement $\$ 20 \%$, and 8-hour daily maximum air quality data. The first 11 lines contain header information. Thereafter, the data are in two sections: the top (lines 12-50) and bottom (54-92) sections are for the highest and fifth highest ozone concentrations, respectively. Each section contains three lines of data for each air quality scenario, one line for each of the benchmarks (i.e., $1 \%, 5 \%$, and 10\%). The six fields in a data line specify the site (monitor) number, the air quality scenario (NAAQS), the air quality dataset, $\mathrm{N}$ of the $n$ 'th highest distribution, the response benchmark, and the benchmark risk. Although each output file contains results for 10 scenarios, the graphics software allows you to include only 9 of the scenarios. 
TABLE A.5 Benchmark Risk Results File

Line

Number

1

2

3

4

5

6

7

8

9

10

11

12

13

14

15

16

17

18

19

20

21

22

23

24

25

26

27

28

29

30

31

32

33

34

35

36

37

38

39
Contents of Line

\author{
BENCHMARK RISK COMPUTATION \\ Philadelphia
}

Horst-Foll-McDon, FEV1>20\%, 6.6 Hr, Moder Exer

AQ Probability Distrib.

$\begin{array}{cccc}\text { Ozone } & \text { N of } & \text { Resp. } & \text { Bnchmrk } \\ \text { Concentration } & \begin{array}{c}\text { Nth High } \\ \text { Distrib. }\end{array} & \text { Bnchmrk } & \text { Risk } \\ & & \end{array}$

\begin{tabular}{|c|c|c|c|c|c|}
\hline 01 & As Is & Daily Max 8 Hr Avg & 1 & 0.01 & 1.000 \\
\hline 01 & As Is & Daily Max 8 Hr Avg & 1 & 0.05 & 1.000 \\
\hline 01 & As Is & Daily Max 8 Hr Avg & 1 & 0.10 & 0.985 \\
\hline
\end{tabular}

$03 \quad 0.09$ ppm Daily Max 8 Hr, 5 exex

Daily Max 8 Hr Avg 1

$\begin{array}{ll}0.01 & 1.000\end{array}$

$03 \quad 0.09$ ppm Daily Max $8 \mathrm{Hr}, 5$ exex

Daily Max 8 Hr Avg 1

$0.05 \quad 0.982$

$0.10 \quad 0.808$

$03 \quad 0.09$ ppm Daily Max 8 Hr, 5 exex

Daily Max 8 Hr Avg 1

$0.01 \quad 1.000$

$0.05 \quad 0.978$

$0.10 \quad 0.777$

$04 \quad 0.09$ ppm Daily Max 8 Hr, 1 exex

Daily Max $8 \mathrm{Hr}$ Avg 1

Daily Max $8 \mathrm{Hr}$ Avg 1

$0.01 \quad 1.000$

$0.05 \quad 0.960$

$0.10 \quad 0.665$

$03 \quad 0.08$ ppm Daily Max $8 \mathrm{Hr}, 5$ exex

Daily Max $8 \mathrm{Hr}$ Avg 1

Daily Max 8 Hr Avg 1

$\begin{array}{ll}0.01 & 1.000\end{array}$

$0.05 \quad 0.950$

$0.10 \quad 0.614$

040.08 ppm Daily Max 8 Hr, 1 exex

Daily Max 8 Hr Avg 1

Daily Max 8 Hr Avg 1

Daily Max 8 Hr Avg 1

$\begin{array}{ll}0.01 & 1.000\end{array}$

$0.05 \quad 0.991$

$0.10 \quad 0.877$

$04 \quad 0.12$ ppm Daily Max $1 \mathrm{Hr}, 1$ exex

Daily Max 8 Hr Avg 1

Daily Max 8 Hr Avg 1

0.01

1.000

$04 \quad 0.10$ ppm Daily Max $1 \mathrm{Hr}, 1$ exex

Daily Max 8 Hr Avg 1

0.05

0.950

$\begin{array}{ll}\text { Daily Max } 8 \mathrm{Hr} \text { Avg } & 1 \\ \text { Daily Max } 8 \mathrm{Hr} \text { Avg } & 1\end{array}$

0.10

0.614

$04 \quad 0.10$ ppm Daily Max $1 \mathrm{Hr}, 1$ exex

Daily Max 8 Hr Avg 1 
TABLE A.5 (Cont.)

\begin{tabular}{|c|c|c|c|c|c|c|}
\hline $\begin{array}{l}\text { Line } \\
\text { Number }\end{array}$ & $\begin{array}{l}\text { Site } \\
\text { No. }\end{array}$ & NAAQS & $\begin{array}{c}\text { Ozone } \\
\text { Concentration }\end{array}$ & $\begin{array}{c}\mathrm{N} \text { of } \\
\text { Nth High } \\
\text { Distrib. }\end{array}$ & $\begin{array}{c}\text { Resp. } \\
\text { Bnchmrk }\end{array}$ & $\begin{array}{c}\text { Bnchmrk } \\
\text { Risk }\end{array}$ \\
\hline 40 & 04 & 0.10 ppm Daily Max $8 \mathrm{Hr}, 1$ exex & Daily Max $8 \mathrm{Hr}$ Avg & 1 & 0.01 & 1.000 \\
\hline 41 & 04 & 0.10 ppm Daily Max $8 \mathrm{Hr}, 1$ exex & Daily Max $8 \mathrm{Hr}$ Avg & 1 & 0.05 & 0.992 \\
\hline 42 & 04 & 0.10 ppm Daily Max $8 \mathrm{Hr}, 1$ exex & Daily Max $8 \mathrm{Hr}$ Avg & 1 & 0.10 & 0.884 \\
\hline \multicolumn{7}{|l|}{43} \\
\hline 44 & 04 & 0.07 ppm Daily Max $8 \mathrm{Hr}, 1$ exex & Daily Max $8 \mathrm{Hr}$ Avg & 1 & 0.01 & 0.999 \\
\hline 45 & 04 & 0.07 ppm Daily Max $8 \mathrm{Hr}, 1$ exex & Daily Max 8 Hr Avg & 1 & 0.05 & 0.734 \\
\hline 46 & 04 & 0.07 ppm Daily Max $8 \mathrm{Hr}, 1$ exex & Daily Max 8 Hr Avg & 1 & 0.10 & 0.195 \\
\hline \multicolumn{7}{|l|}{47} \\
\hline 48 & 03 & 0.06 ppm Daily Max $8 \mathrm{Hr}, 5$ exex & Daily Max $8 \mathrm{Hr}$ Avg & 1 & 0.01 & 0.959 \\
\hline 49 & 03 & 0.06 ppm Daily Max 8 Hr, 5 exex & Daily Max $8 \mathrm{Hr}$ Avg & 1 & 0.05 & 0.341 \\
\hline 50 & 03 & 0.06 ppm Daily Max 8 Hr, 5 exex & Daily Max $8 \mathrm{Hr}$ Avg & 1 & 0.10 & 0.037 \\
\hline \multicolumn{7}{|l|}{51} \\
\hline \multicolumn{7}{|l|}{52} \\
\hline \multicolumn{7}{|l|}{53} \\
\hline 54 & 01 & As Is & Daily Max $8 \mathrm{Hr}$ Avg & 5 & 0.01 & 1.000 \\
\hline 55 & 01 & As Is & Daily Max $8 \mathrm{Hr}$ Avg & 5 & 0.05 & 0.999 \\
\hline 56 & 01 & As Is & Daily Max $8 \mathrm{Hr}$ Avg & 5 & 0.10 & 0.960 \\
\hline \multicolumn{7}{|l|}{57} \\
\hline 58 & 03 & 0.09 ppm Daily Max $8 \mathrm{Hr}, 5$ exex & Daily Max $8 \mathrm{Hr}$ Avg & 5 & 0.01 & 1.000 \\
\hline 59 & 03 & 0.09 ppm Daily Max 8 Hr, 5 exex & Daily Max 8 Hr Avg & 5 & 0.05 & 0.967 \\
\hline 60 & 03 & 0.09 ppm Daily Max 8 Hr, 5 exex & Daily Max $8 \mathrm{Hr}$ Avg & 5 & 0.10 & 0.698 \\
\hline \multicolumn{7}{|c|}{ 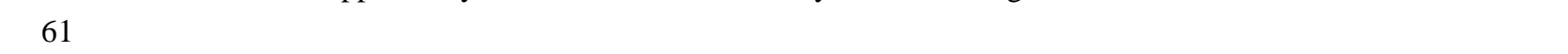 } \\
\hline 62 & 04 & 0.09 ppm Daily Max $8 \mathrm{Hr}, 1$ exex & Daily Max $8 \mathrm{Hr}$ Avg & 5 & 0.01 & 1.000 \\
\hline 63 & 04 & 0.09 ppm Daily Max $8 \mathrm{Hr}, 1$ exex & Daily Max $8 \mathrm{Hr}$ Avg & 5 & 0.05 & 0.965 \\
\hline 64 & 04 & 0.09 ppm Daily Max $8 \mathrm{Hr}, 1$ exex & Daily Max $8 \mathrm{Hr}$ Avg & 5 & 0.10 & 0.688 \\
\hline \multicolumn{7}{|c|}{ - } \\
\hline 66 & 03 & 0.08 ppm Daily Max 8 Hr, 5 exex & Daily Max 8 Hr Avg & 5 & 0.01 & 1.000 \\
\hline 67 & 03 & 0.08 ppm Daily Max 8 Hr, 5 exex & Daily Max 8 Hr Avg & 5 & 0.05 & 0.920 \\
\hline 68 & 03 & 0.08 ppm Daily Max 8 Hr, 5 exex & Daily Max $8 \mathrm{Hr}$ Avg & 5 & 0.10 & 0.482 \\
\hline \multicolumn{7}{|l|}{69} \\
\hline 70 & 04 & 0.08 ppm Daily Max $8 \mathrm{Hr}, 1$ exex & Daily Max 8 Hr Avg & 5 & 0.01 & 1.000 \\
\hline 71 & 04 & 0.08 ppm Daily Max $8 \mathrm{Hr}, 1$ exex & Daily Max $8 \mathrm{Hr}$ Avg & 5 & 0.05 & 0.918 \\
\hline 72 & 04 & 0.08 ppm Daily Max $8 \mathrm{Hr}, 1$ exex & Daily Max $8 \mathrm{Hr}$ Avg & 5 & 0.10 & 0.471 \\
\hline \multicolumn{7}{|c|}{ 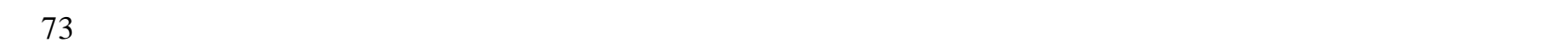 } \\
\hline 74 & 04 & 0.12 ppm Daily Max $1 \mathrm{Hr}, 1$ exex & Daily Max $8 \mathrm{Hr}$ Avg & 5 & 0.01 & 1.000 \\
\hline 75 & 04 & 0.12 ppm Daily Max $1 \mathrm{Hr}, 1$ exex & Daily Max $8 \mathrm{Hr}$ Avg & 5 & 0.05 & 0.969 \\
\hline 76 & 04 & 0.12 ppm Daily Max $1 \mathrm{Hr}, 1$ exex & Daily Max 8 Hr Avg & 5 & 0.10 & 0.715 \\
\hline \multicolumn{7}{|l|}{77} \\
\hline 78 & 04 & 0.10 ppm Daily Max $1 \mathrm{Hr}, 1$ exex & Daily Max 8 Hr Avg & 5 & 0.01 & 1.000 \\
\hline 79 & 04 & 0.10 ppm Daily Max $1 \mathrm{Hr}, 1$ exex & Daily Max $8 \mathrm{Hr}$ Avg & 5 & 0.05 & 0.918 \\
\hline 80 & 04 & $0.10 \mathrm{ppm}$ Daily Max $1 \mathrm{Hr}, 1$ exex & Daily Max 8 Hr Avg & 5 & 0.10 & 0.471 \\
\hline
\end{tabular}


TABLE A.5 (Cont.)

\begin{tabular}{|c|c|c|c|c|c|c|}
\hline $\begin{array}{l}\text { Line } \\
\text { Number }\end{array}$ & $\begin{array}{l}\text { Site } \\
\text { No. }\end{array}$ & NAAQS & $\begin{array}{c}\text { Ozone } \\
\text { Concentration }\end{array}$ & $\begin{array}{c}\mathrm{N} \text { of } \\
\text { Nth High } \\
\text { Distrib. }\end{array}$ & $\begin{array}{c}\text { Resp. } \\
\text { Bnchmrk }\end{array}$ & $\begin{array}{l}\text { Bnchmrk } \\
\text { Risk }\end{array}$ \\
\hline \multicolumn{7}{|l|}{81} \\
\hline 82 & 04 & 0.10 ppm Daily Max 8 Hr, 1 exex & Daily Max 8 Hr Avg & 5 & 0.01 & 1.000 \\
\hline 83 & 04 & 0.10 ppm Daily Max $8 \mathrm{Hr}, 1$ exex & Daily Max 8 Hr Avg & 5 & 0.05 & 0.984 \\
\hline 84 & 04 & 0.10 ppm Daily Max $8 \mathrm{Hr}, 1$ exex & Daily Max 8 Hr Avg & 5 & 0.10 & 0.821 \\
\hline \multicolumn{7}{|c|}{ 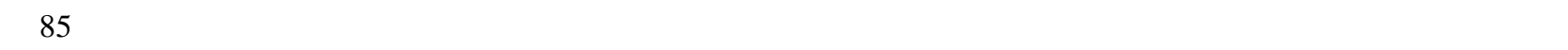 } \\
\hline 86 & 04 & 0.07 ppm Daily Max $8 \mathrm{Hr}, 1$ exex & Daily Max 8 Hr Avg & 5 & 0.01 & 0.998 \\
\hline 87 & 04 & 0.07 ppm Daily Max $8 \mathrm{Hr}, 1$ exex & Daily Max 8 Hr Avg & 5 & 0.05 & 0.727 \\
\hline 88 & 04 & 0.07 ppm Daily Max $8 \mathrm{Hr}, 1$ exex & Daily Max 8 Hr Avg & 5 & 0.10 & 0.193 \\
\hline \multicolumn{7}{|l|}{89} \\
\hline 90 & 03 & 0.06 ppm Daily Max 8 Hr, 5 exex & Daily Max 8 Hr Avg & 5 & 0.01 & 0.958 \\
\hline 91 & 03 & 0.06 ppm Daily Max 8 Hr, 5 exex & Daily Max 8 Hr Avg & 5 & 0.05 & 0.340 \\
\hline 92 & 03 & 0.06 ppm Daily Max 8 Hr, 5 exex & Daily Max 8 Hr Avg & 5 & 0.10 & 0.037 \\
\hline \multicolumn{7}{|c|}{11} \\
\hline \multicolumn{7}{|l|}{94} \\
\hline 95 & & & & & & \\
\hline
\end{tabular}




\section{APPENDIX B:}

\section{INFORMATION ABOUT HEALTH ENDPOINTS AND AIR QUALITY SCENARIOS USED IN ORAMUS}

The tables in this appendix provide additional information about acute health endpoints and air quality scenarios used in the Ozone Risk AssessMent UtilitieS (ORAMUS) software system. Table B.1 provides references for the human exposure studies used to develop acute health endpoints (symptoms and lung function). Table B.2 lists the air quality scenarios available for each of nine urban areas for acute health endpoints. 
TABLE B.1 Human Exposure Studies that Support Acute Health Endpoints (symptoms and lung function)

\begin{tabular}{|c|c|c|c|c|c|c|}
\hline \multicolumn{2}{|r|}{ Endpoint } & \multicolumn{3}{|c|}{ 1-hour Exposures at Heavy Exertion } & \multirow{2}{*}{$\begin{array}{l}\text { 1-hour Exposures at } \\
\text { Moderate Exertion } \\
\\
\text { Seal et al. (1993) } \\
\end{array}$} & \multirow{2}{*}{$\begin{array}{c}\text { 8-hour Exposures at } \\
\text { Moderate Exertion }\end{array}$} \\
\hline Code & Description & $\begin{array}{l}\text { McDonnell } \\
\text { et al. (1983) }\end{array}$ & $\begin{array}{c}\text { Avol et al. } \\
(1984)\end{array}$ & $\begin{array}{c}\text { Kulle et al. } \\
\text { (1985) }\end{array}$ & & \\
\hline F10 & $\mathrm{FEV}_{1}$ decrement $\$ 10 \%$ & $\mathrm{Yes}^{\mathrm{a}}$ & Yes & Yes & Yes & Yes \\
\hline F15 & $\mathrm{FEV}_{1}$ decrement $\$ 15 \%$ & Yes & Yes & Yes & Yes & Yes \\
\hline F20 & $\mathrm{FEV}_{1}$ decrement $\$ 20 \%$ & Yes & Yes & Yes & Yes & Yes \\
\hline $\mathrm{ACF}$ & Any cough & Yes & $\mathrm{No}^{\mathrm{b}}$ & Yes & Yes & Yes \\
\hline APD & $\begin{array}{l}\text { Any pain on deep } \\
\text { inspiration }\end{array}$ & Yes & No & Yes & Yes & Yes \\
\hline ALR & $\begin{array}{l}\text { Any lower respiratory } \\
\text { symptoms }\end{array}$ & No & Yes & No & No & No \\
\hline $\mathrm{MCF}$ & Moderate-to-severe cough & Yes & No & Yes & Yes & Yes \\
\hline MPD & $\begin{array}{l}\text { Moderate-to-severe pain on } \\
\text { deep inspiration }\end{array}$ & Yes & No & Yes & Yes & Yes \\
\hline MLR & $\begin{array}{l}\text { Moderate-to-severe lower } \\
\text { respiratory symptoms }\end{array}$ & No & Yes & No & No & No \\
\hline
\end{tabular}

a Yes means the study supports the endpoint associated with the row.

b No means the study does not support the endpoint associated with the row. 
64

TABLE B.2 Air Quality Scenarios Available for Acute Risk Assessments (symptoms and lung function; persons and person-occurrences)

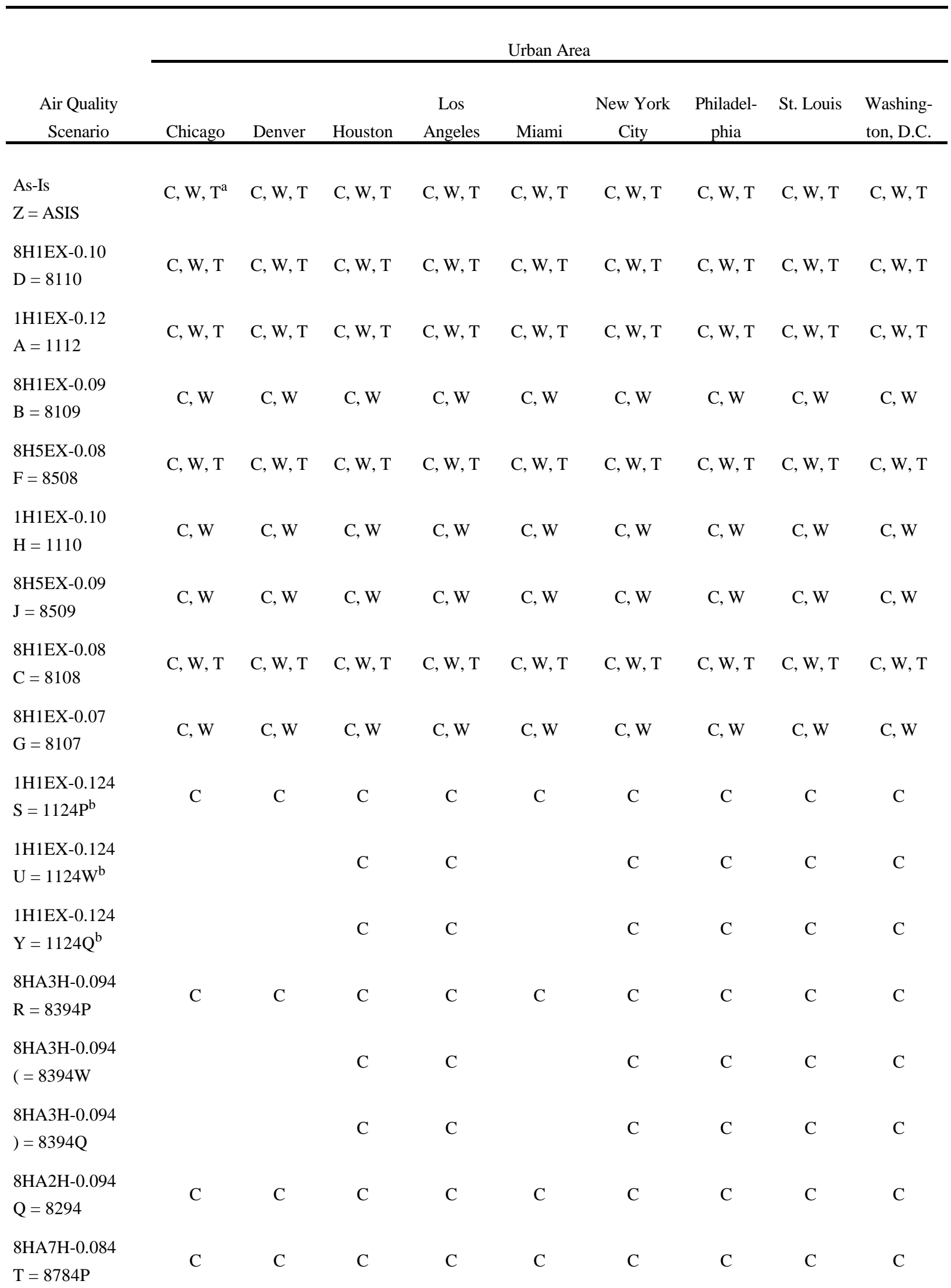


TABLE B.2 (Cont.)

\begin{tabular}{|c|c|c|c|c|c|c|c|c|c|}
\hline \multirow[b]{2}{*}{$\begin{array}{c}\text { Air Quality } \\
\text { Scenario } \\
\end{array}$} & \multicolumn{9}{|c|}{ Urban Area } \\
\hline & Chicago & Denver & Houston & $\begin{array}{c}\text { Los } \\
\text { Angeles } \\
\end{array}$ & Miami & $\begin{array}{c}\text { New York } \\
\text { City }\end{array}$ & $\begin{array}{c}\text { Philadel- } \\
\text { phia }\end{array}$ & St. Louis & $\begin{array}{l}\text { Washing- } \\
\text { ton, D.C. }\end{array}$ \\
\hline $\begin{array}{l}8 \mathrm{HA} 7 \mathrm{H}-0.084 \\
\mathrm{~V}=8784 \mathrm{~W}\end{array}$ & & & $\mathrm{C}$ & $\mathrm{C}$ & & $\mathrm{C}$ & $\mathrm{C}$ & $\mathrm{C}$ & $\mathrm{C}$ \\
\hline $\begin{array}{l}8 \mathrm{HA7H}-0.084 \\
\mathrm{I}=8784 \mathrm{Q}\end{array}$ & & & $\mathrm{C}$ & $\mathrm{C}$ & & $\mathrm{C}$ & $\mathrm{C}$ & $\mathrm{C}$ & $\mathrm{C}$ \\
\hline $\begin{array}{l}8 \mathrm{HA} 5 \mathrm{H}-0.084 \\
\mathrm{~N}=8584 \mathrm{P}\end{array}$ & $\mathrm{C}$ & C & $\mathrm{C}$ & $\mathrm{C}$ & $\mathrm{C}$ & $\mathrm{C}$ & $\mathrm{C}$ & C & $\mathrm{C}$ \\
\hline $\begin{array}{l}8 \mathrm{HA} 5 \mathrm{H}-0.084 \\
\mathrm{~W}=8584 \mathrm{~W}\end{array}$ & & & $\mathrm{C}$ & $\mathrm{C}$ & & $\mathrm{C}$ & $\mathrm{C}$ & C & $\mathrm{C}$ \\
\hline $\begin{array}{l}8 \mathrm{HA} 5 \mathrm{H}-0.084 \\
\mathrm{~K}=8584 \mathrm{Q}\end{array}$ & & & $\mathrm{C}$ & $\mathrm{C}$ & & $\mathrm{C}$ & C & C & $\mathrm{C}$ \\
\hline $\begin{array}{l}8 \mathrm{HA} 3 \mathrm{H}-0.084 \\
\mathrm{O}=8384 \mathrm{P}\end{array}$ & $\mathrm{C}$ & $\mathrm{C}$ & $\mathrm{C}$ & $\mathrm{C}$ & $\mathrm{C}$ & $\mathrm{C}$ & $\mathrm{C}$ & C & $\mathrm{C}$ \\
\hline $\begin{array}{l}8 \mathrm{HA} 3 \mathrm{H}-0.084 \\
\mathrm{X}=8384 \mathrm{~W}\end{array}$ & & & $\mathrm{C}$ & $\mathrm{C}$ & & $\mathrm{C}$ & C & C & C \\
\hline $\begin{array}{l}8 \mathrm{HA} 3 \mathrm{H}-0.084 \\
\mathrm{~L}=8384 \mathrm{Q}\end{array}$ & & & $\mathrm{C}$ & $\mathrm{C}$ & & $\mathrm{C}$ & $\mathrm{C}$ & $\mathrm{C}$ & $\mathrm{C}$ \\
\hline $\begin{array}{l}8 \mathrm{HA} 2 \mathrm{H}-0.084 \\
\mathrm{M}=8284\end{array}$ & C & $\mathrm{C}$ & $\mathrm{C}$ & $\mathrm{C}$ & $\mathrm{C}$ & $\mathrm{C}$ & C & C & $\mathrm{C}$ \\
\hline $\begin{array}{l}8 \mathrm{HA} 3 \mathrm{H}-0.080 \\
\mathrm{P}=8380\end{array}$ & $\mathrm{C}$ & $\mathrm{C}$ & $\mathrm{C}$ & $\mathrm{C}$ & $\mathrm{C}$ & $\mathrm{C}$ & $\mathrm{C}$ & C & $\mathrm{C}$ \\
\hline
\end{tabular}

a C denotes outdoor children; $\mathrm{W}$ denotes outdoor workers; $\mathrm{T}$ denotes total population; no entry means the scenario is unavailable (for some Chicago, Denver, and Miami scenarios).

b The fifth character denotes the air quality adjustment procedure: $\mathrm{P}$ denotes proportional; $\mathrm{W}$ denotes Weibull; and Q denotes quadratic; no fifth character indicates that a proportional adjustment procedure was used. 


\section{APPENDIX B REFERENCES}

Avol, E.L., et al., 1984, "Comparative Respiratory Effects of Ozone and Ambient Oxidant Pollution Exposure during Heavy Exercise," Journal of the Air Pollution Control Association 34:804-809.

Folinsbee, L.J., et al., 1988, "Pulmonary Function and Symptom Responses after 6.6-Hour Exposure to 0.12 ppm Ozone with Moderate Exercise," JAPCA 38:28-35.

Horstman, D.H., et al., 1990, "Ozone Concentration and Pulmonary Response Relationships for 6.6-Hour Exposures with Five Hours of Moderate Exercise to 0.08, 0.10, and 0.12 ppm," American Review of Respiratory Disease 142:1158-1163.

Kulle, T.J., et al., 1985, "Ozone Response Relationships in Healthy Nonsmokers," American Review of Respiratory Disease 132:36-41.

McDonnell, W.F., et al., 1983, "Pulmonary Effects of Ozone Exposure during Exercise: Dose-Response Characteristics," Journal of Applied Physiology: Respiratory Environmental Exercise Physiology 54:1345-1352.

McDonnell, W.F., et al., 1991, "Respiratory Response of Humans Exposed to Low Levels of Ozone for 6.6 Hours," Archives of Environmental Health 46:145-150.

Seal, E., Jr., et al., 1993, "The Pulmonary Response of White and Black Adults to Six Concentrations of Ozone," American Review of Respiratory Disease 147:804-810. 